\title{
Local Heat Flux Measurements with Single Element Coaxial Injectors
}

\author{
Gregg Jones*, Christopher Protz†, Brad Bullard†, \\ NASA Marshall Space Flight Center, Huntsville, AL, 35812 \\ James Hulka \\ Jacobs Sverdrup, MSFC Group, Huntsville, AL, 35812
}

\section{ABSTRACT}

To support the mission for the NASA Vision for Space Exploration, the NASA Marshall Space Flight Center conducted a program in 2005 to improve the capability to predict local thermal compatibility and heat transfer in liquid propellant rocket engine combustion devices. The ultimate objective was to predict and hence reduce the local peak heat flux due to injector design, resulting in a significant improvement in overall engine reliability and durability. Such analyses are applicable to combustion devices in booster, upper stage, and in-space engines, as well as for small thrusters with few elements in the injector. In this program, single element and three-element injectors were hot-fire tested with liquid oxygen and ambient temperature gaseous hydrogen propellants at The Pennsylvania State University Cryogenic Combustor Laboratory from May to August 2005. Local heat fluxes were measured in a 1-inch internal diameter heat sink combustion chamber using Medtherm coaxial thermocouples and Gardon heat flux gauges. Injectors were tested with shear coaxial and swirl coaxial elements, including recessed, flush and scarfed oxidizer post configurations, and concentric and non-concentric fuel annuli. This paper includes general descriptions of the experimental hardware, instrumentation, and results of the hot-fire testing for three of the single element injectors - recessed-post shear coaxial with concentric fuel, flush-post swirl coaxial with concentric fuel, and scarfed-post swirl coaxial with concentric fuel. Detailed geometry and test results will be published elsewhere to provide well-defined data sets for injector development and model validatation. 

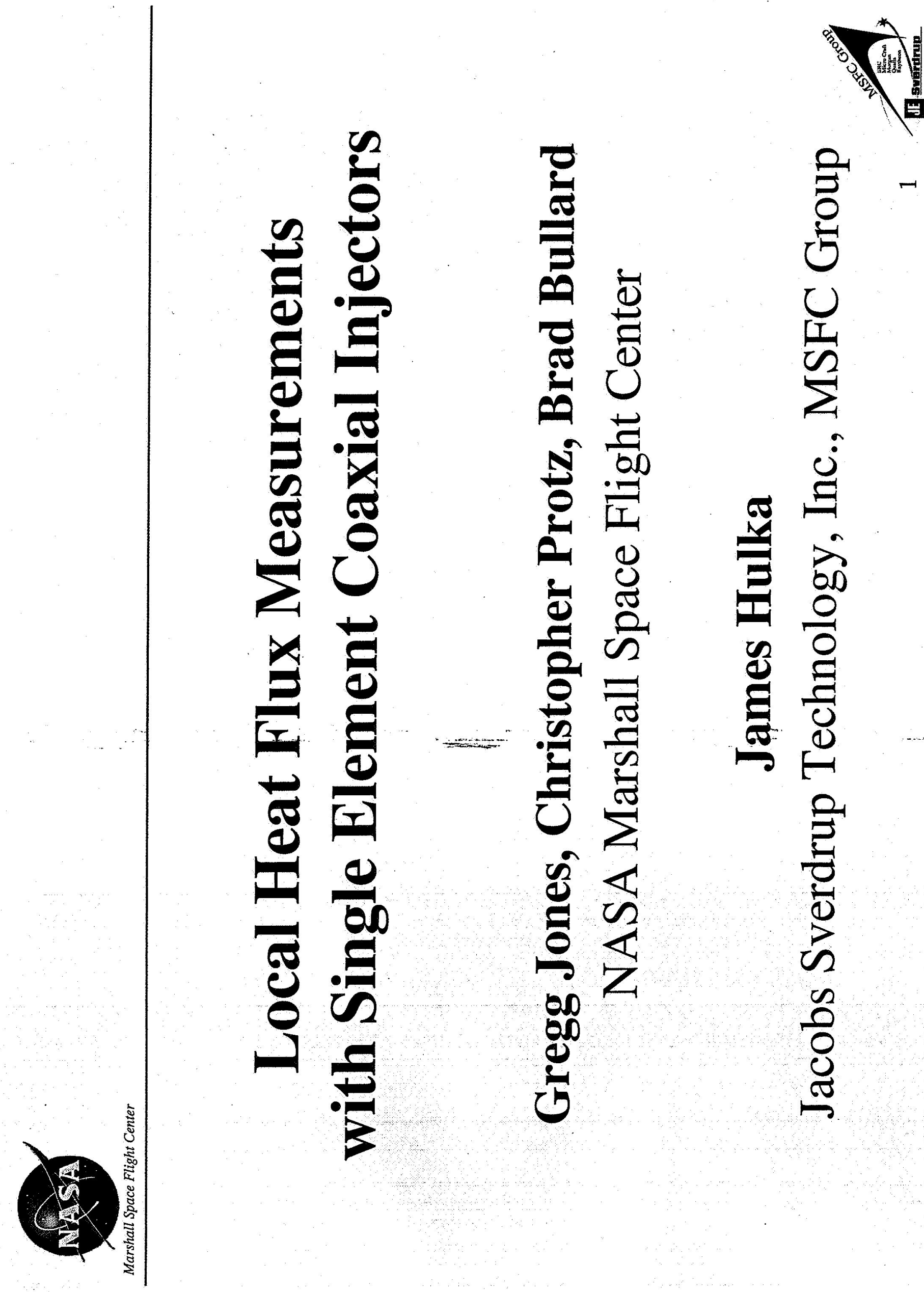

2

0

b

Da

$\Rightarrow \quad 0$

당

है

$\rightarrow E$
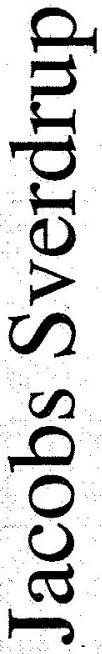


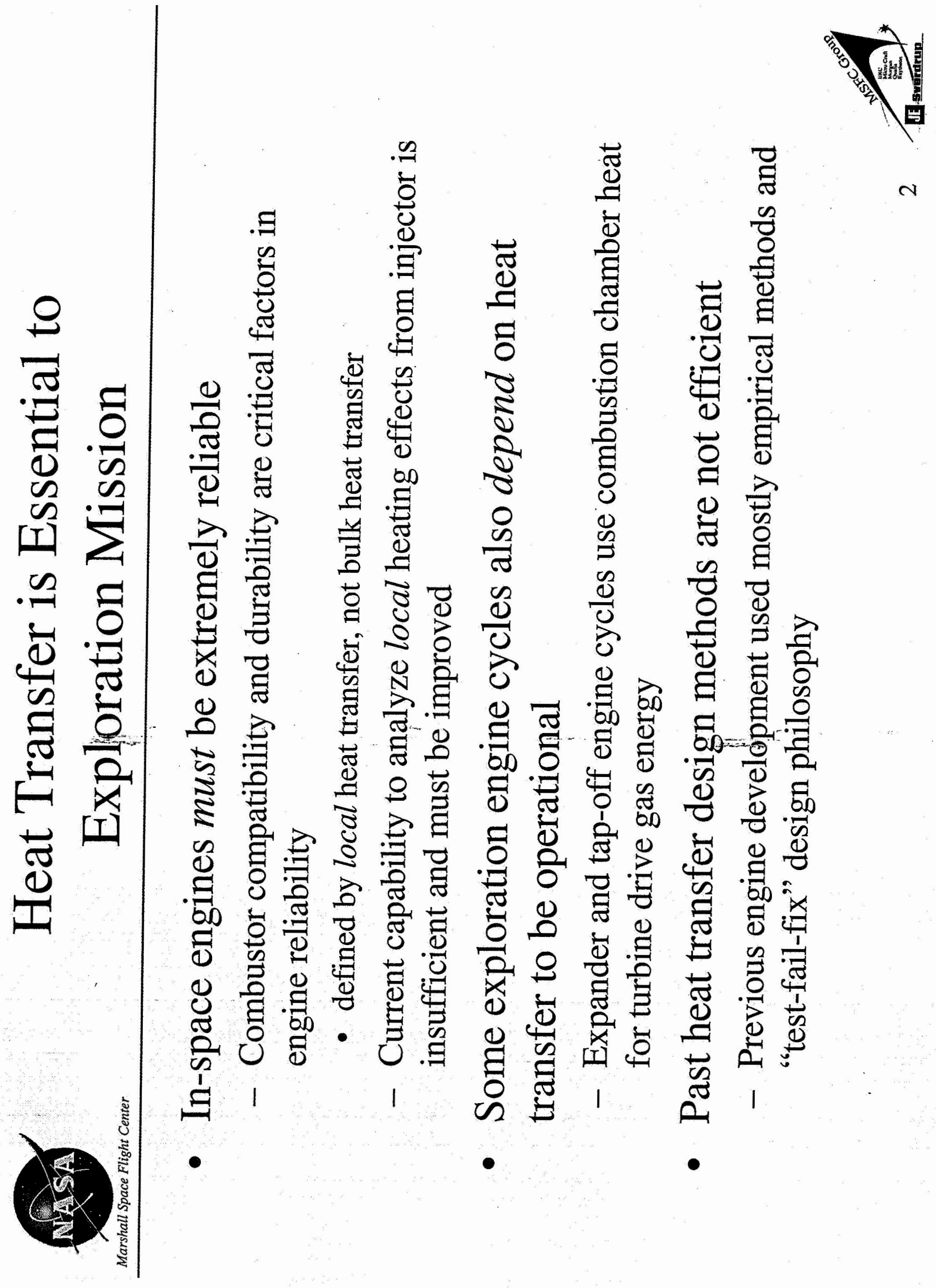




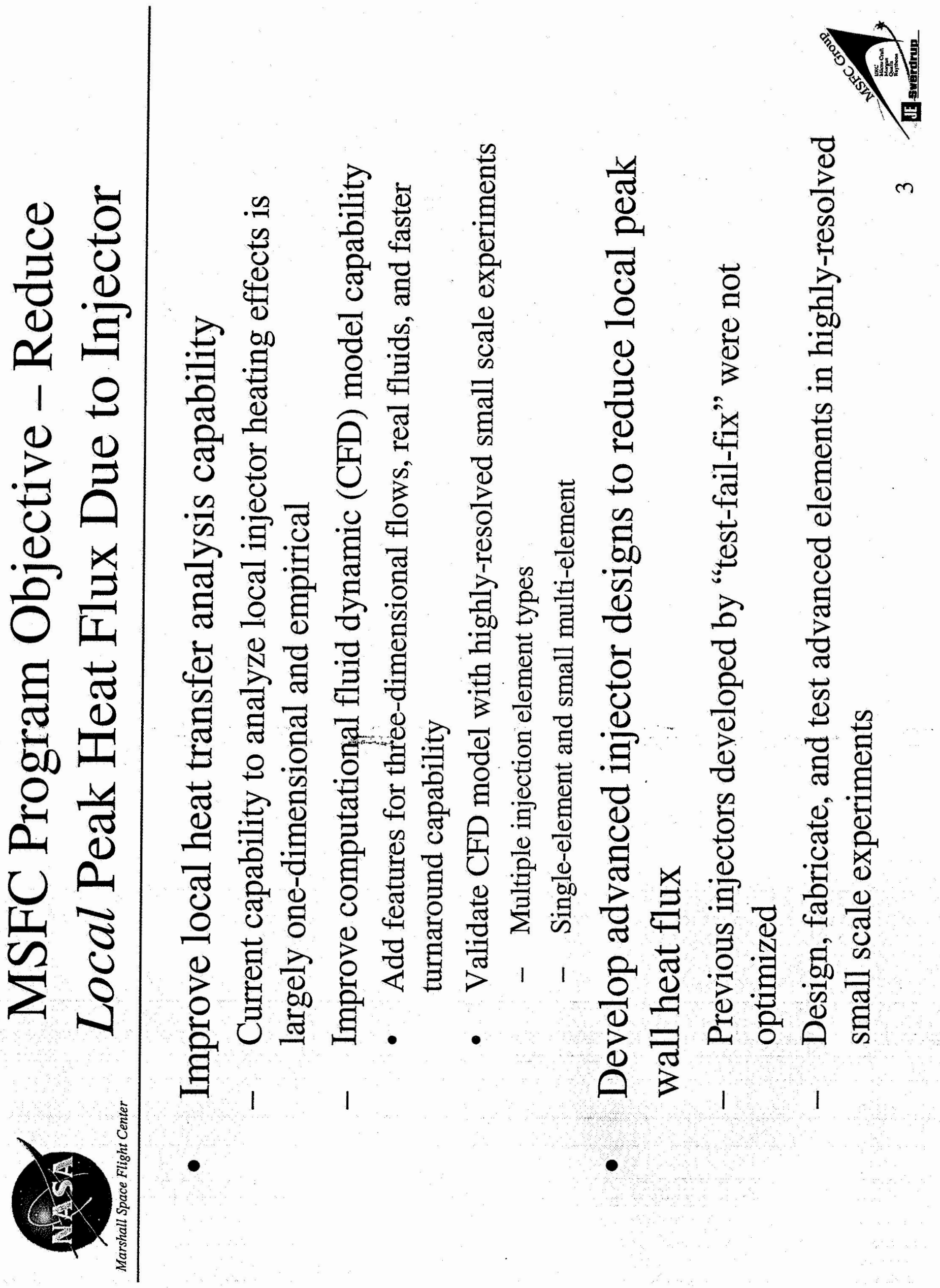




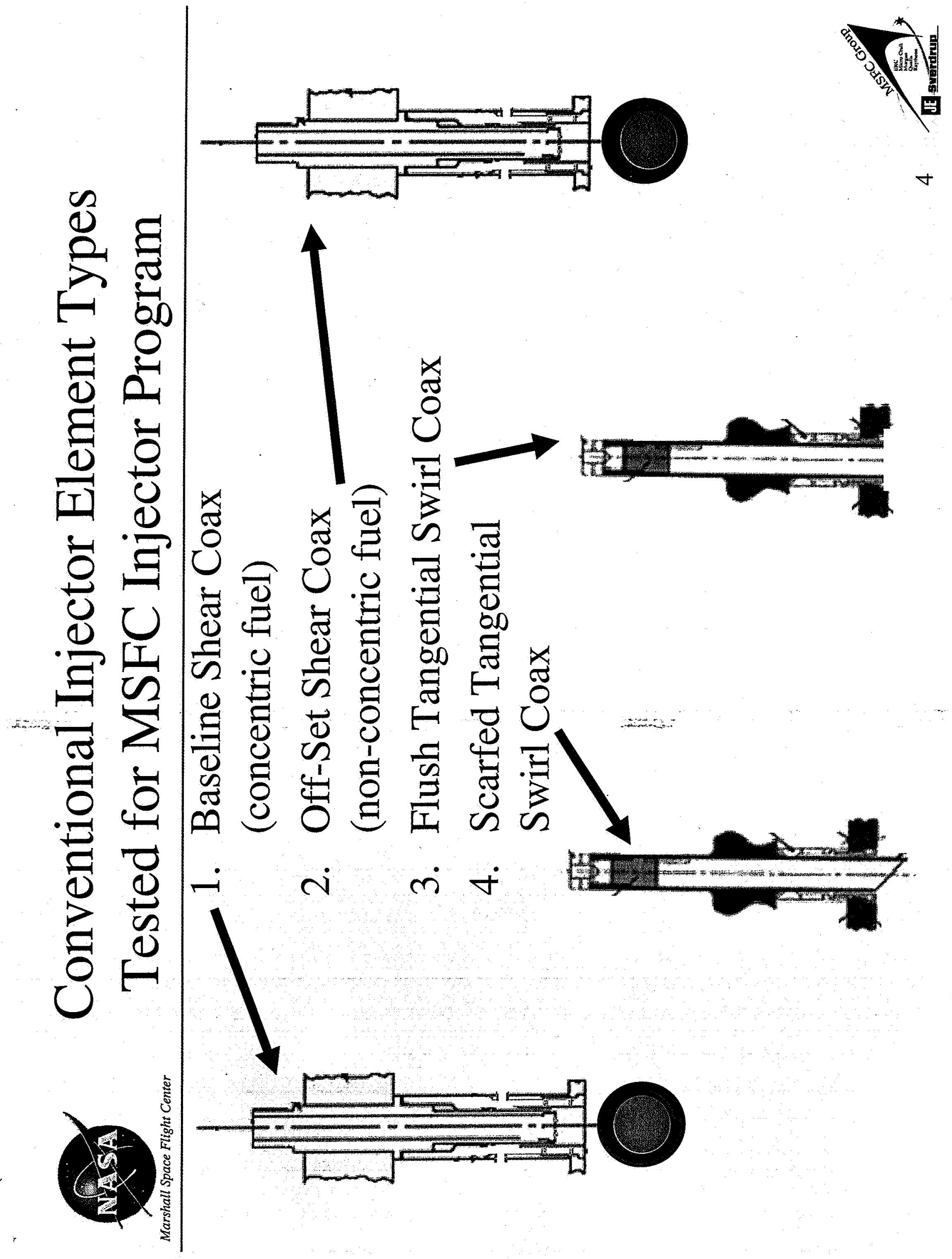




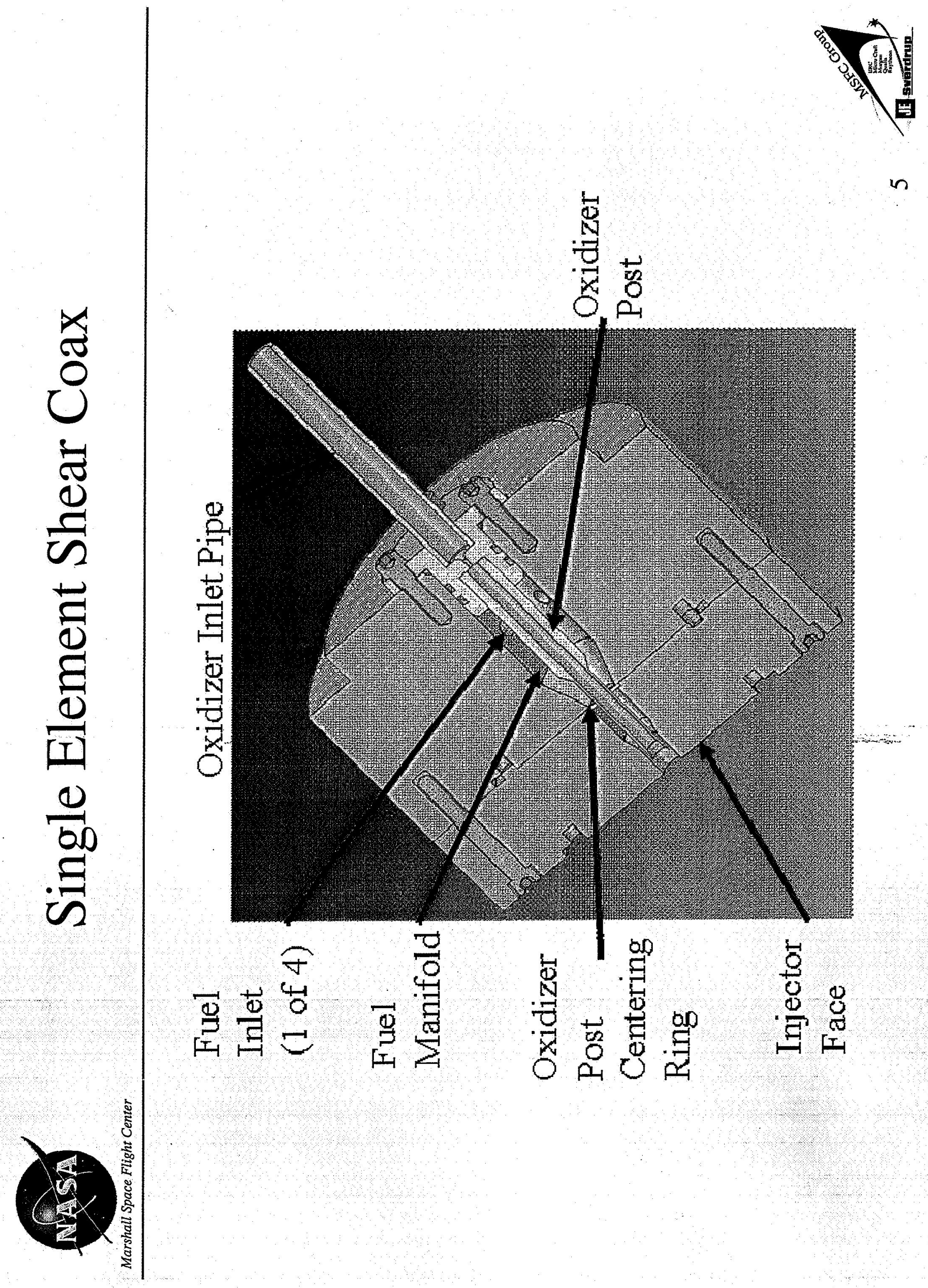




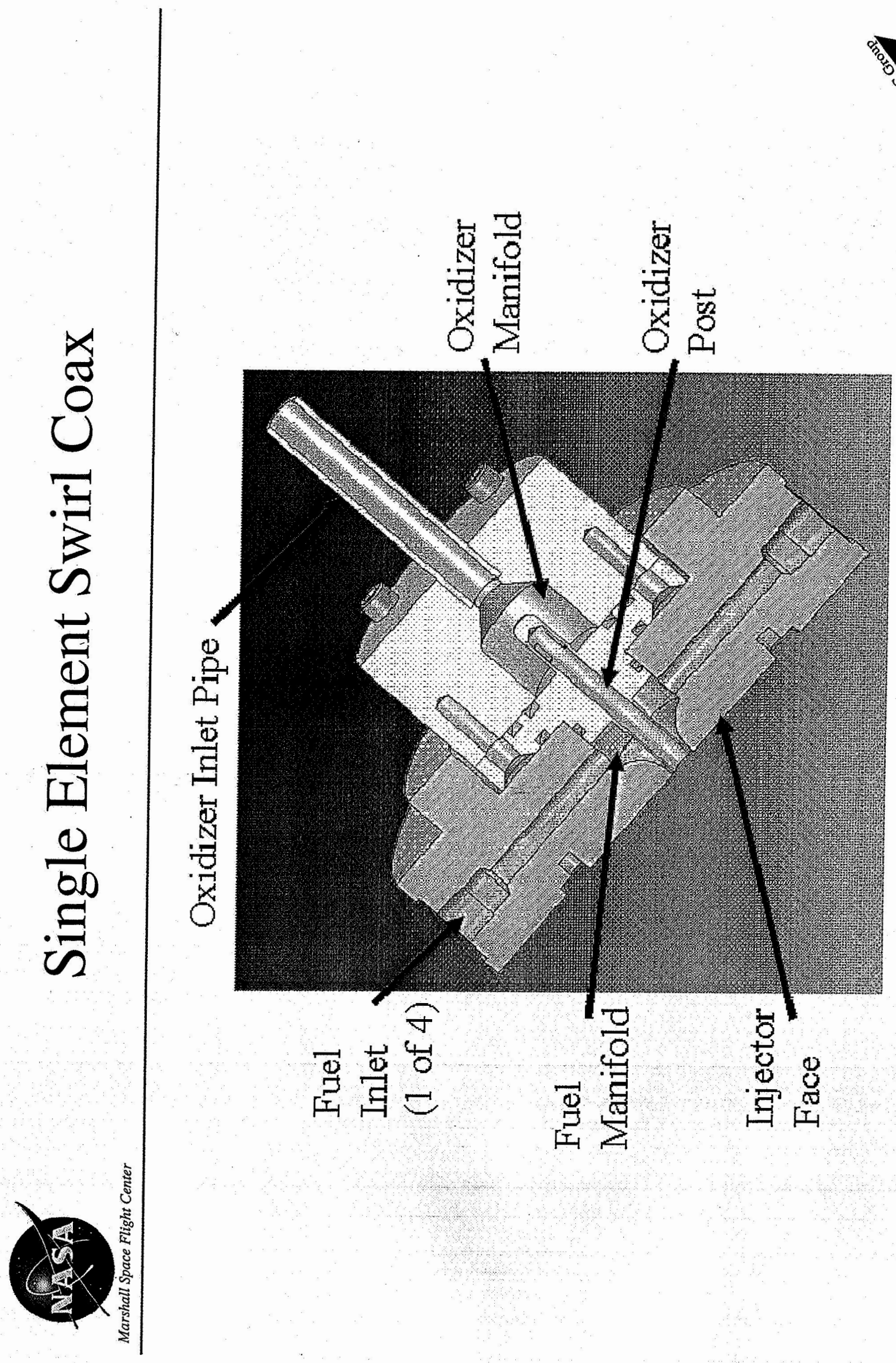




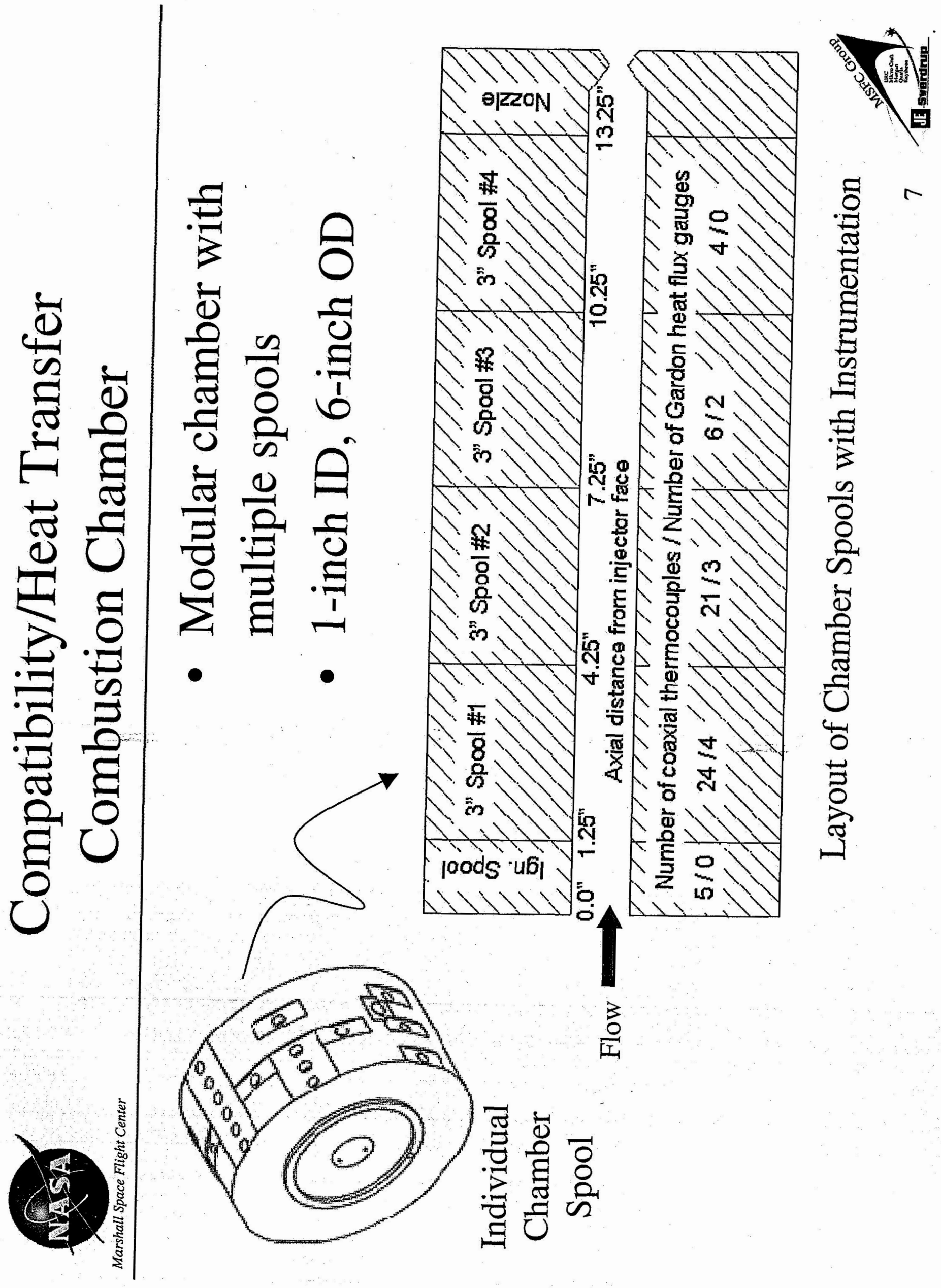




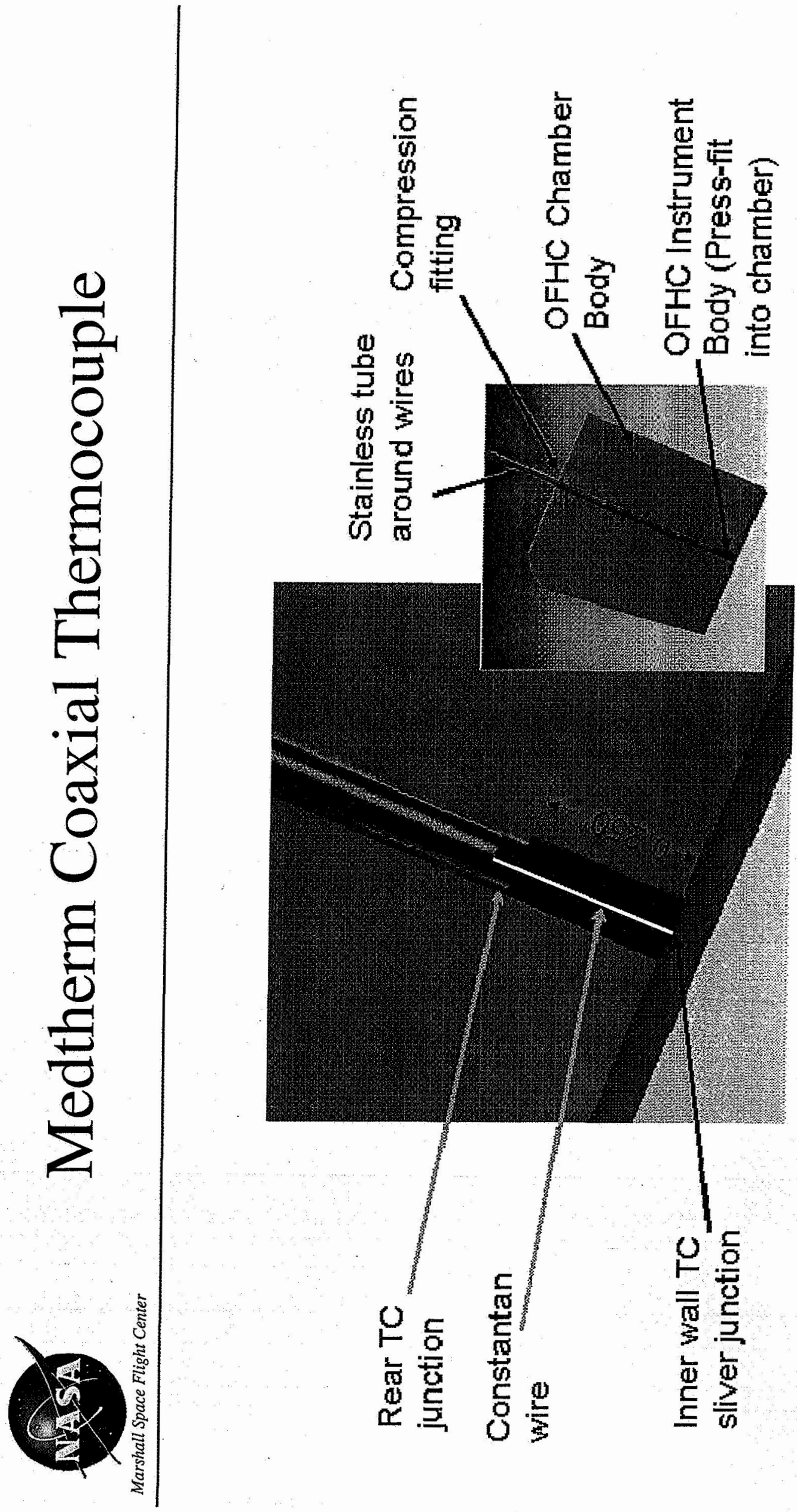




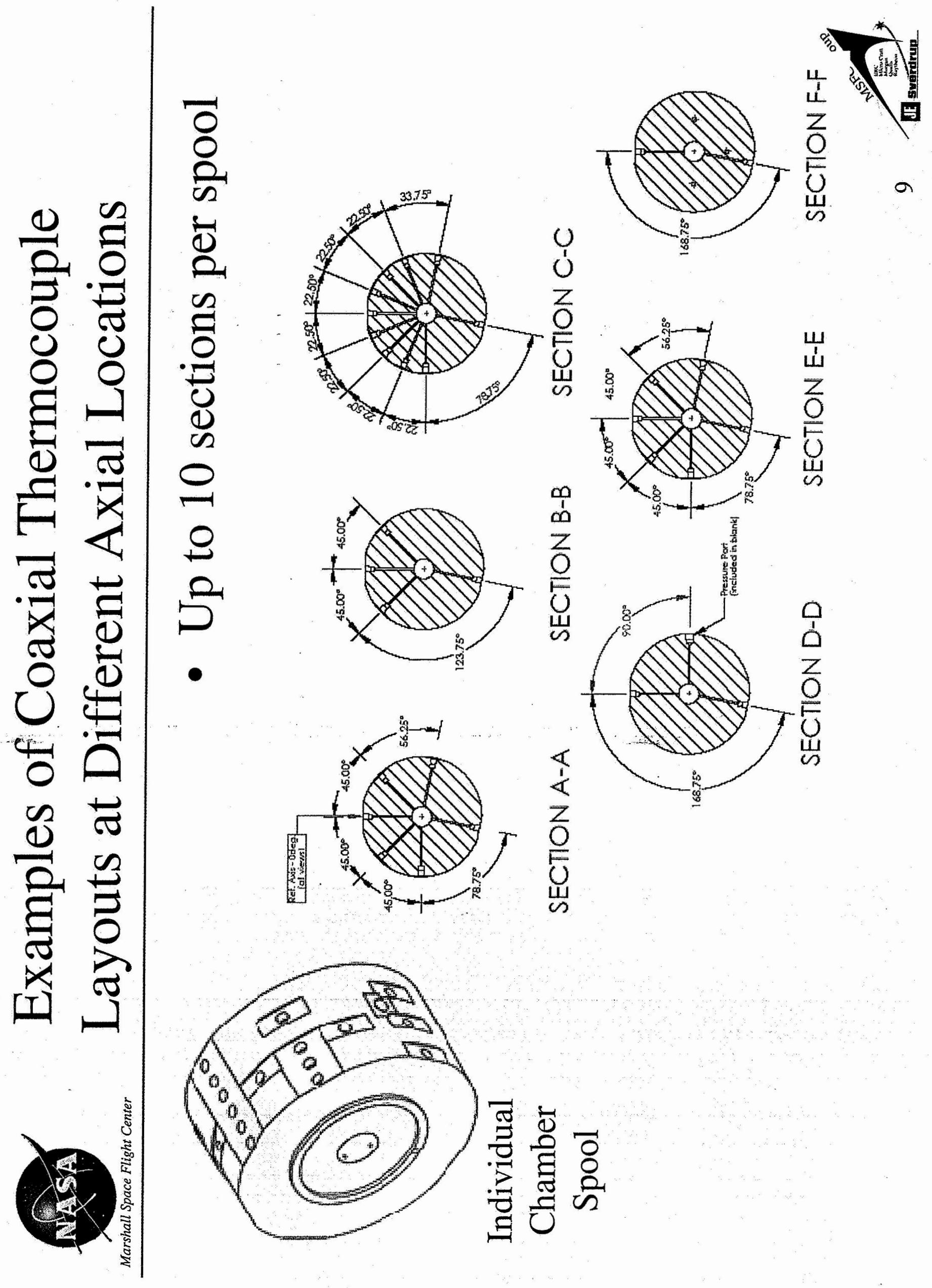




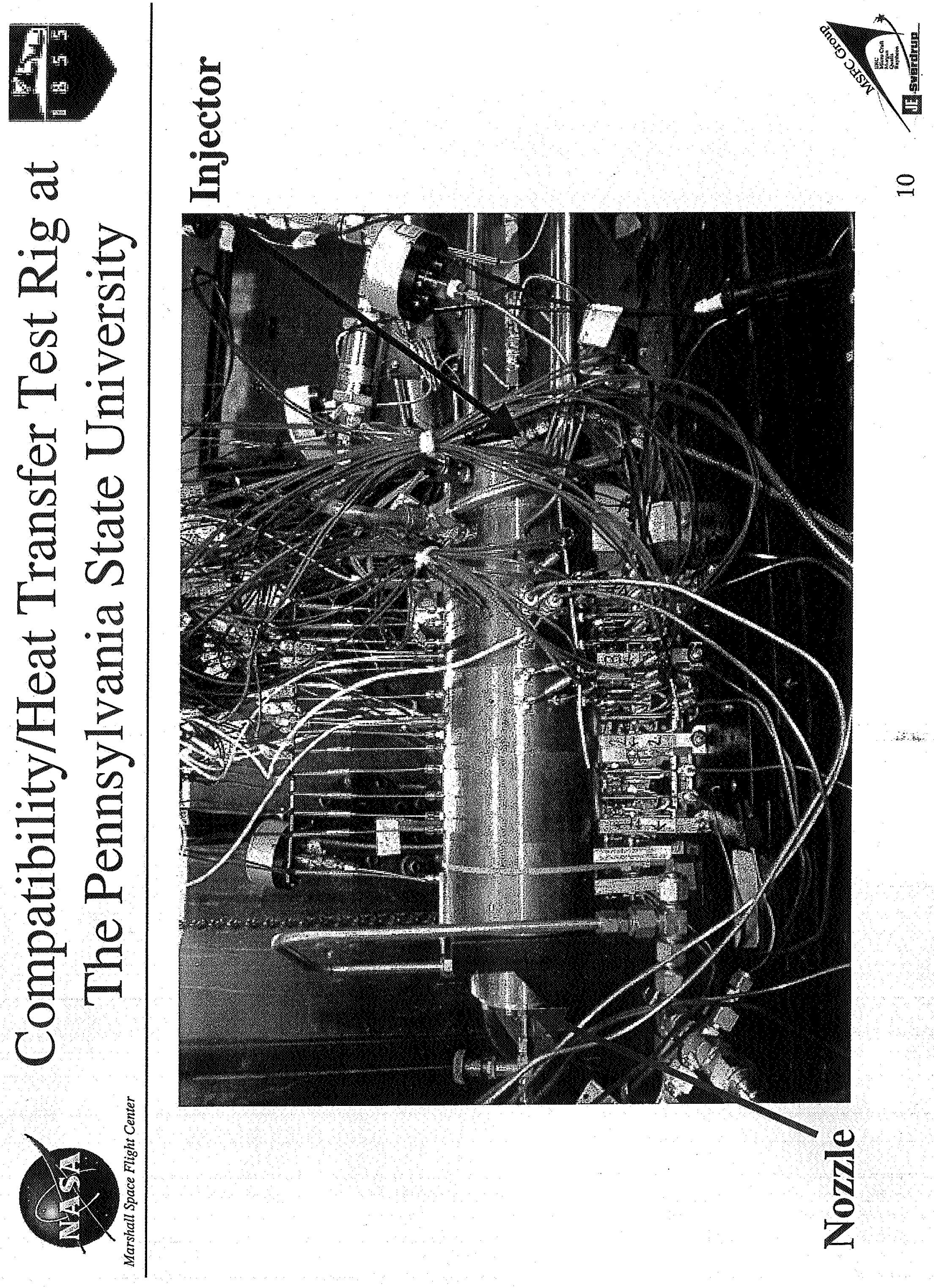




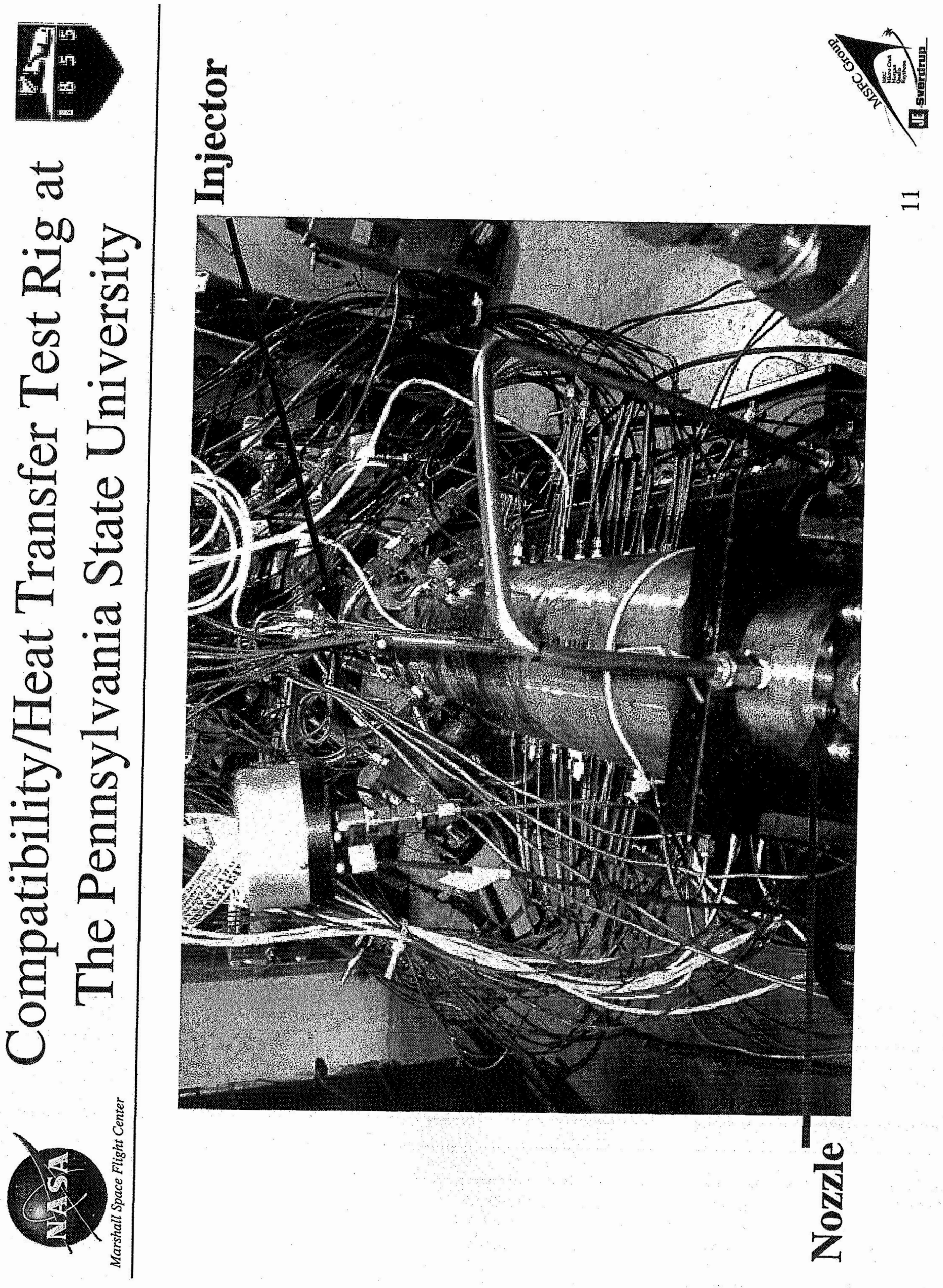




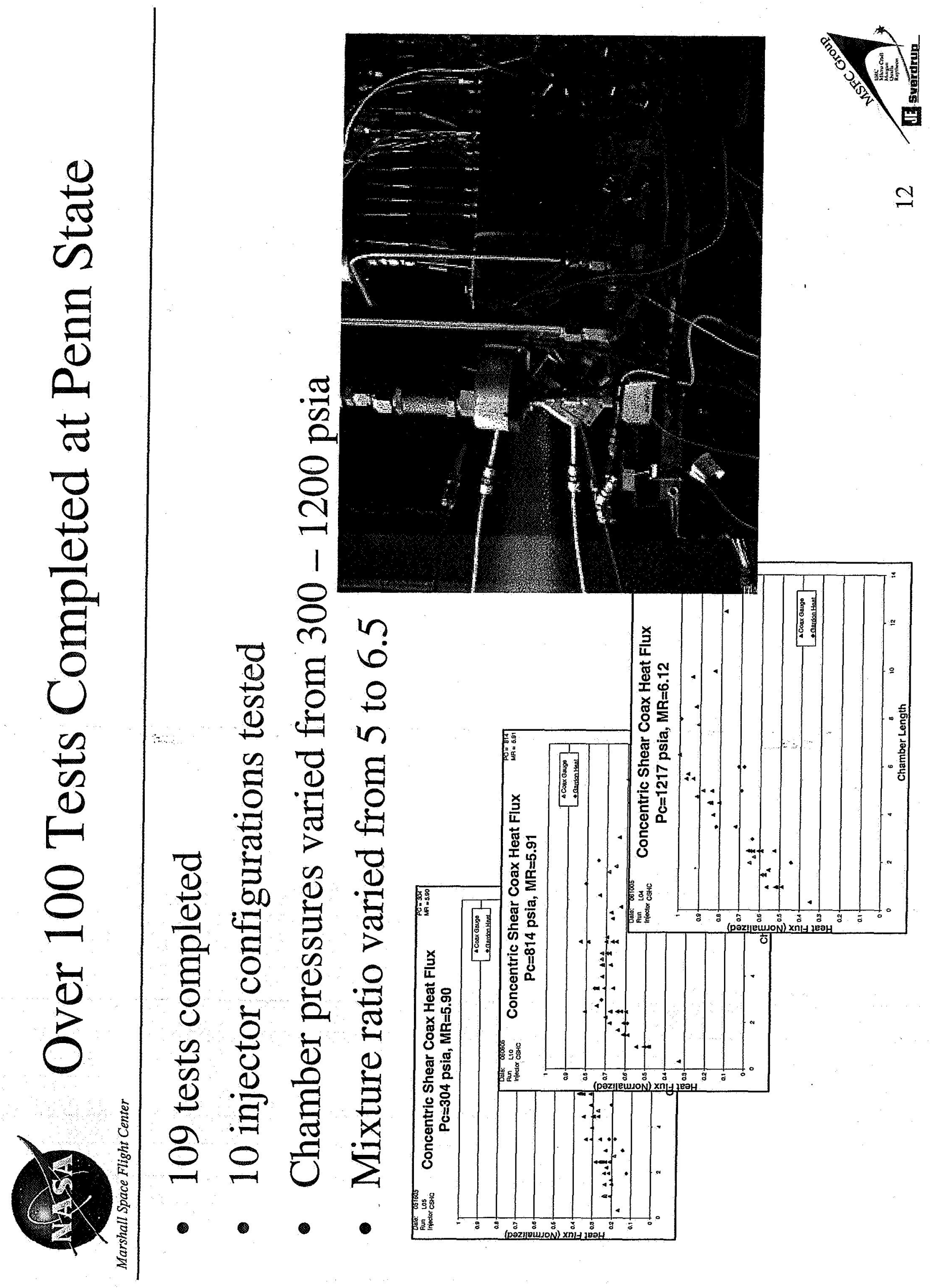




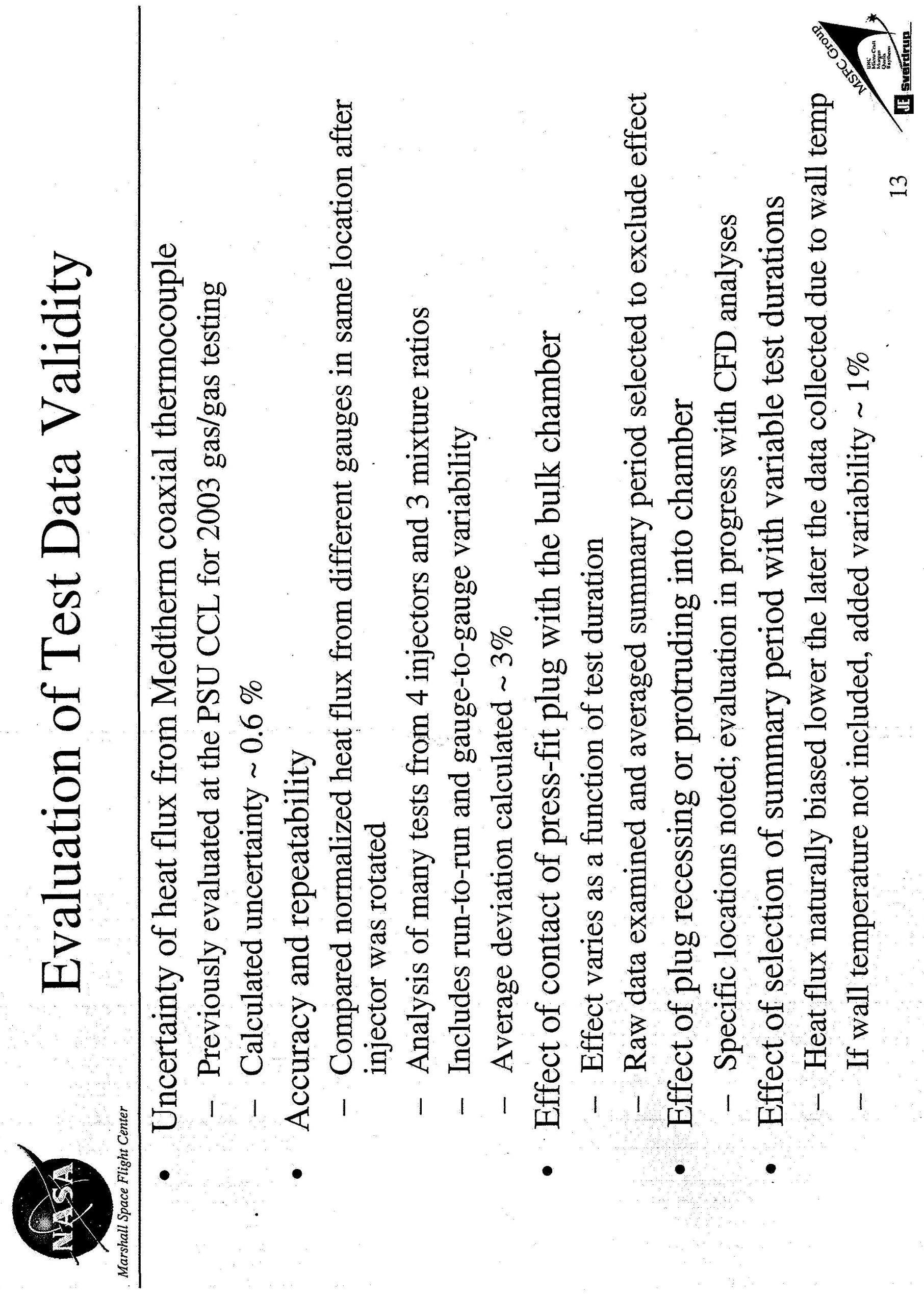




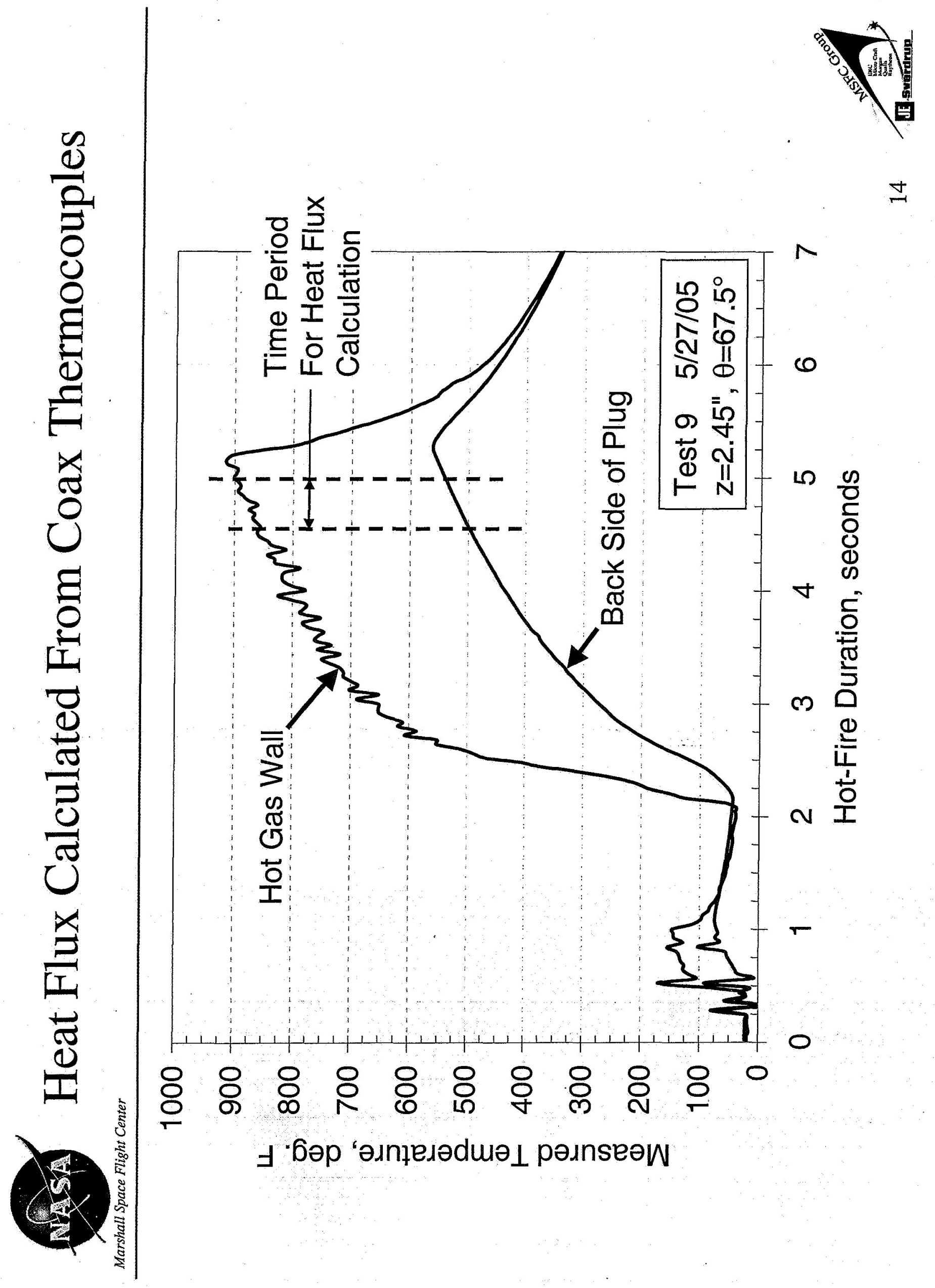




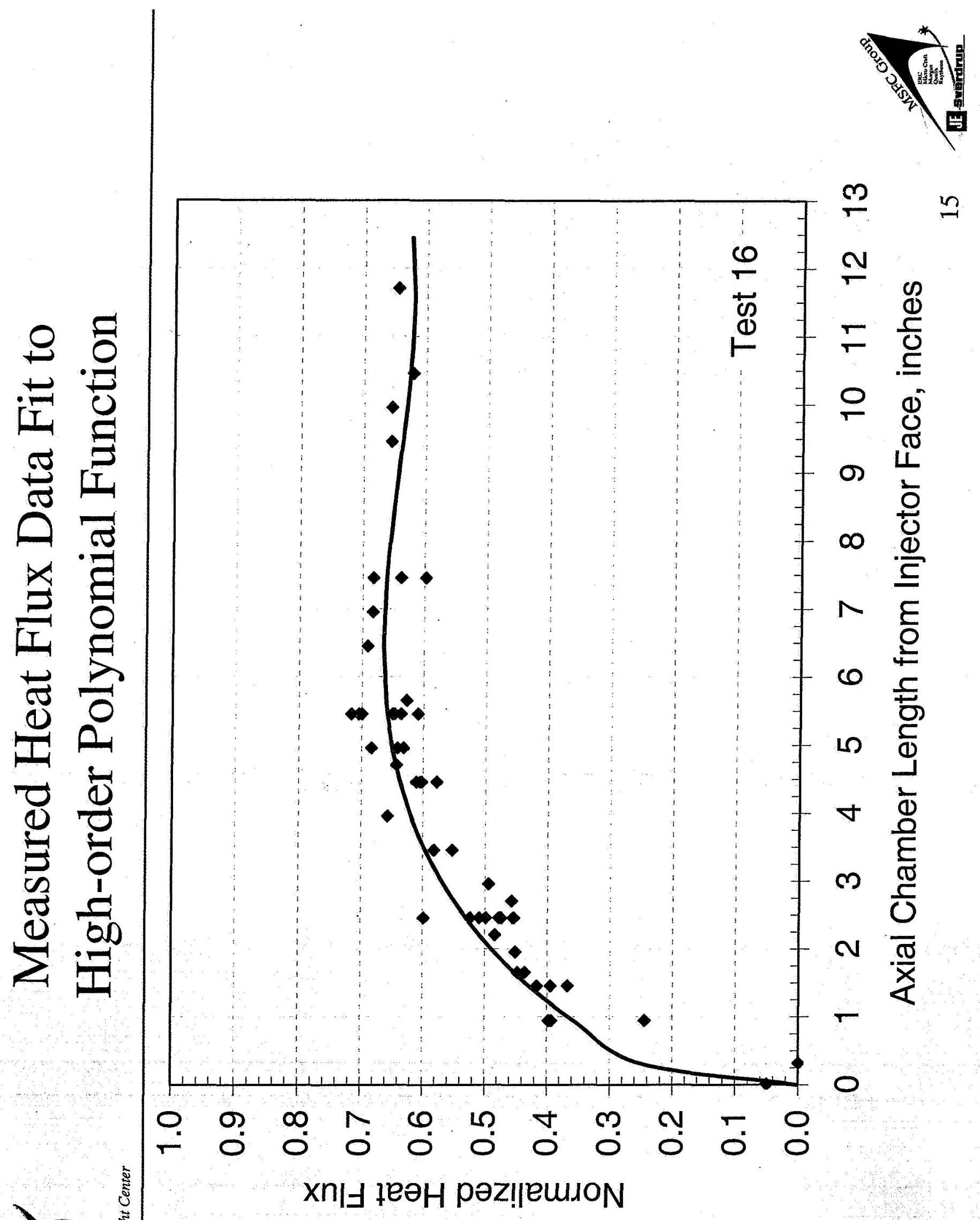




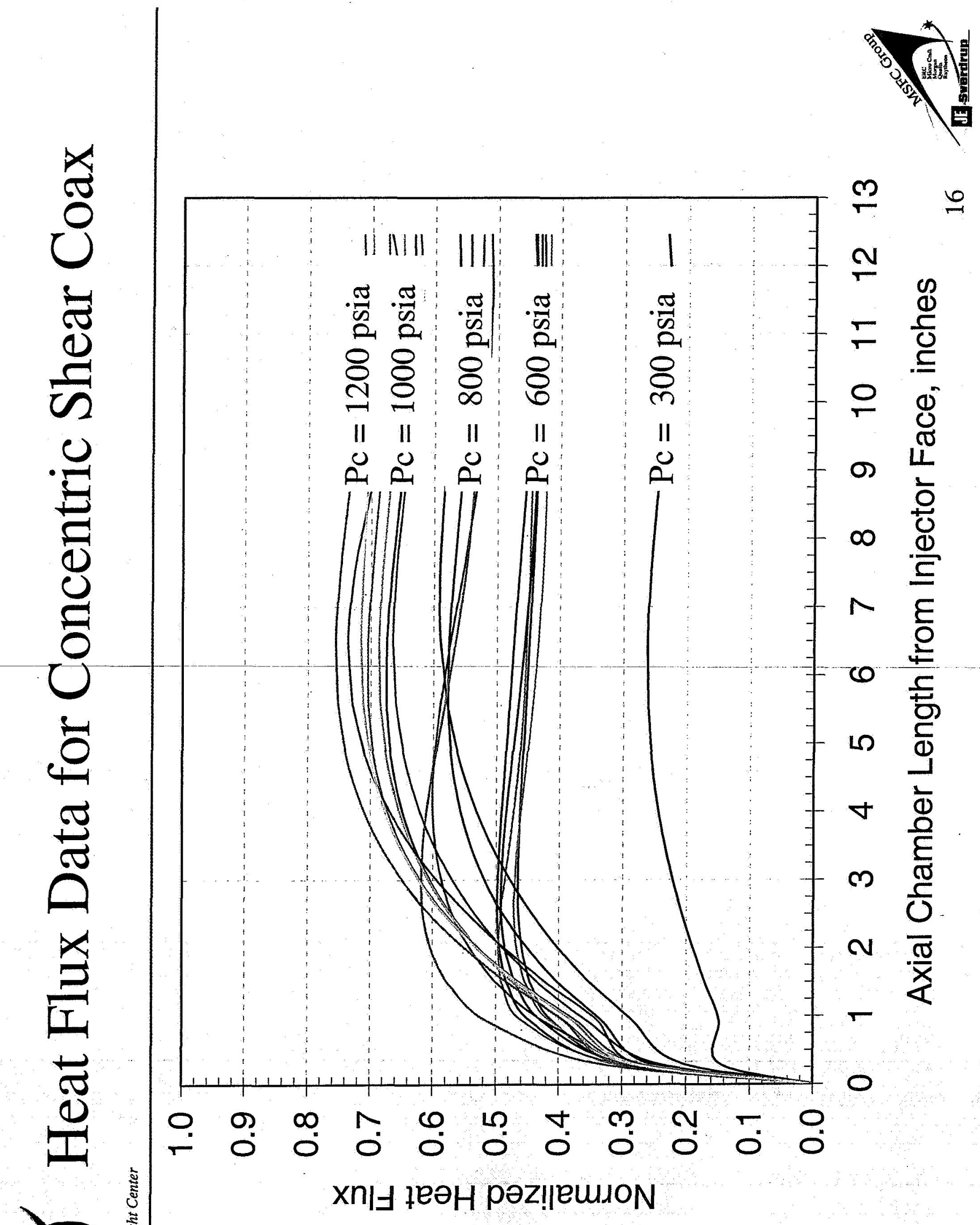




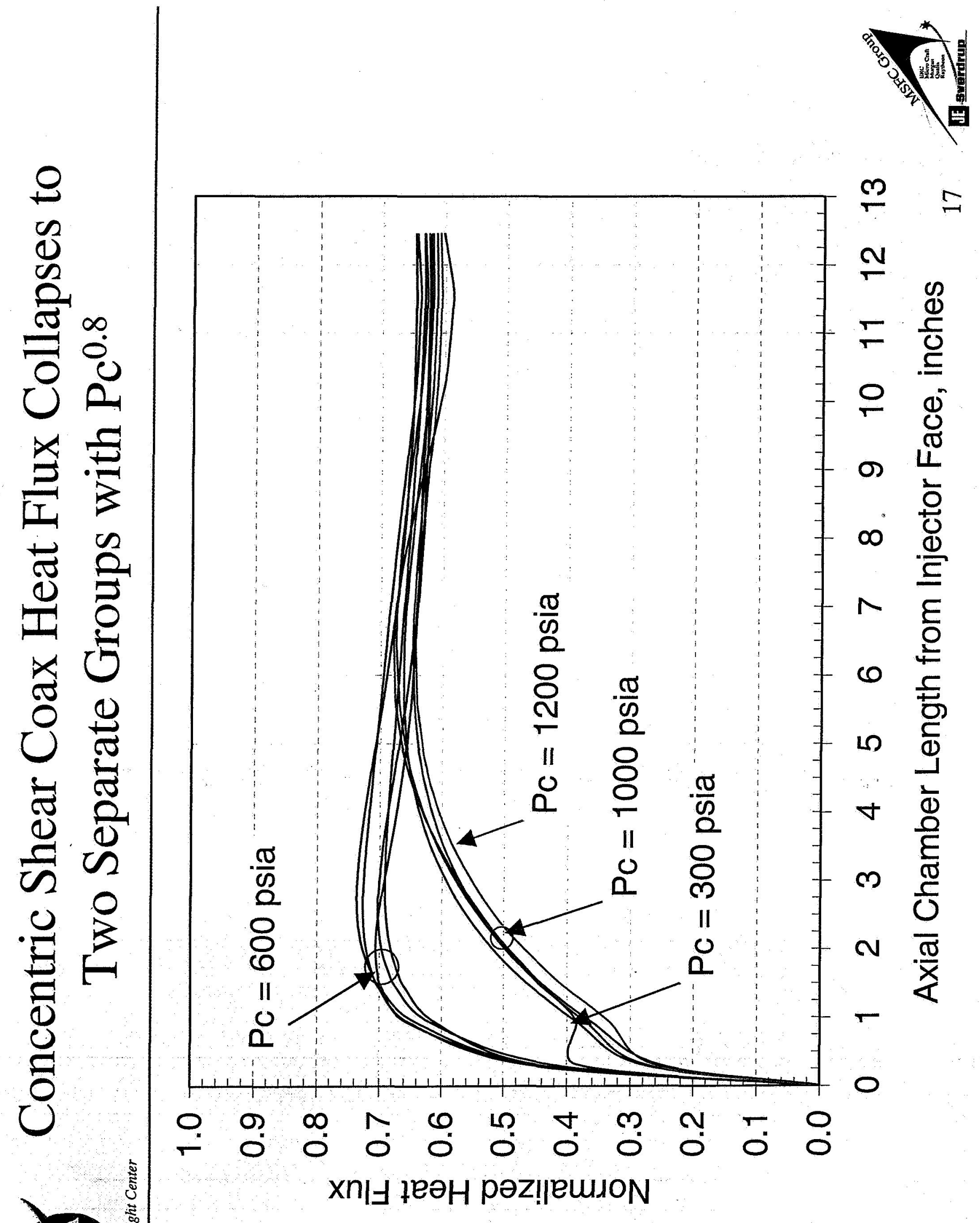




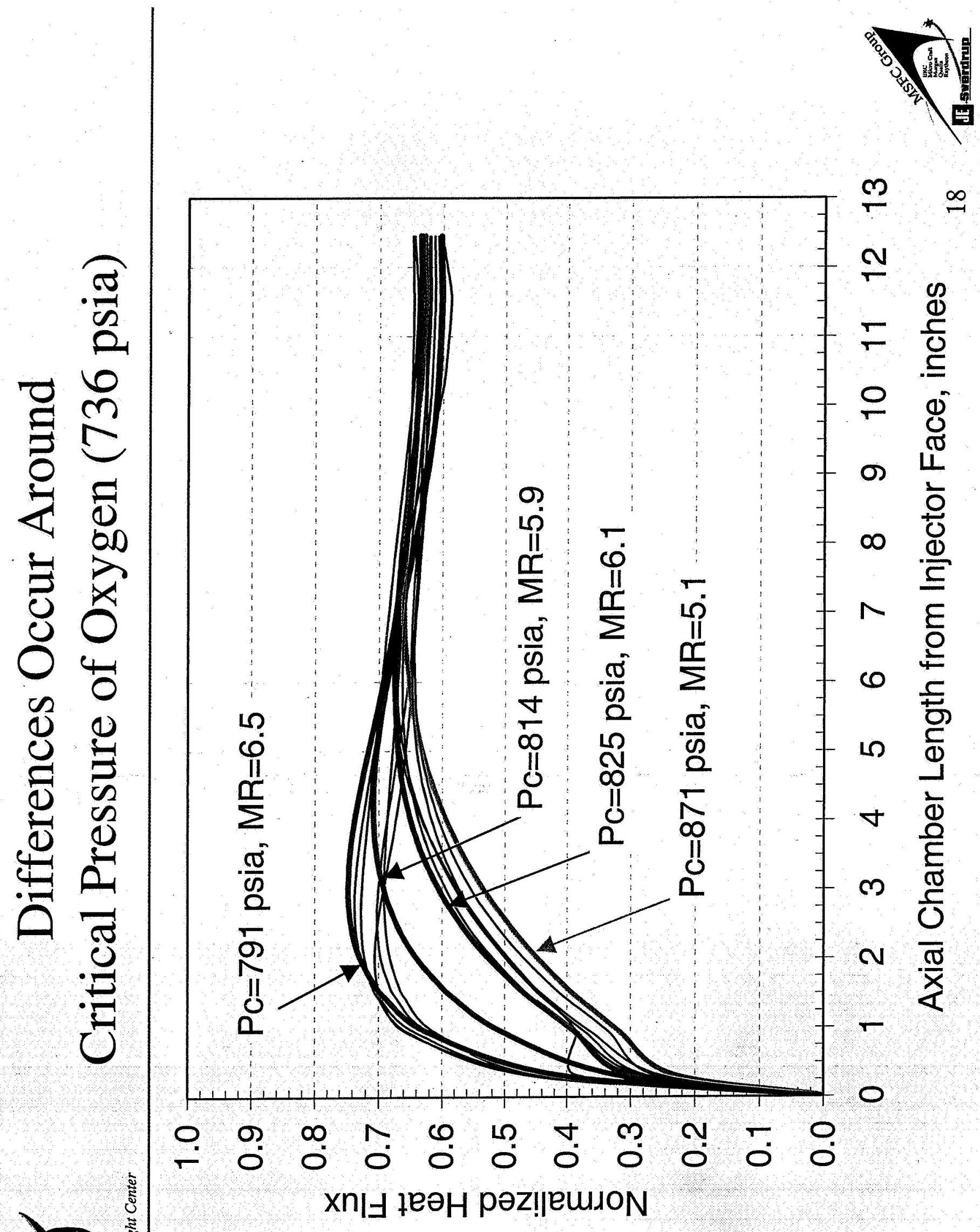




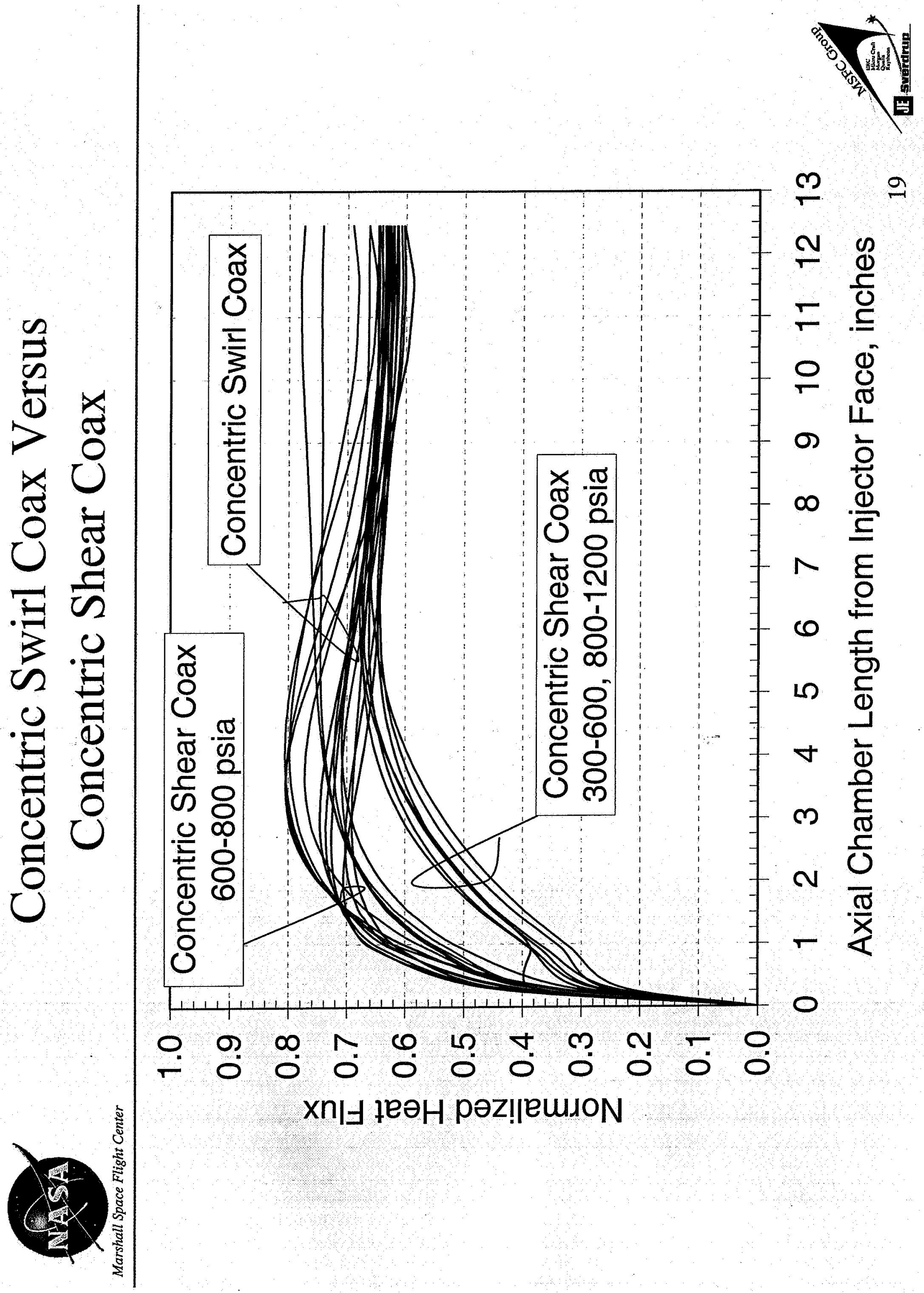




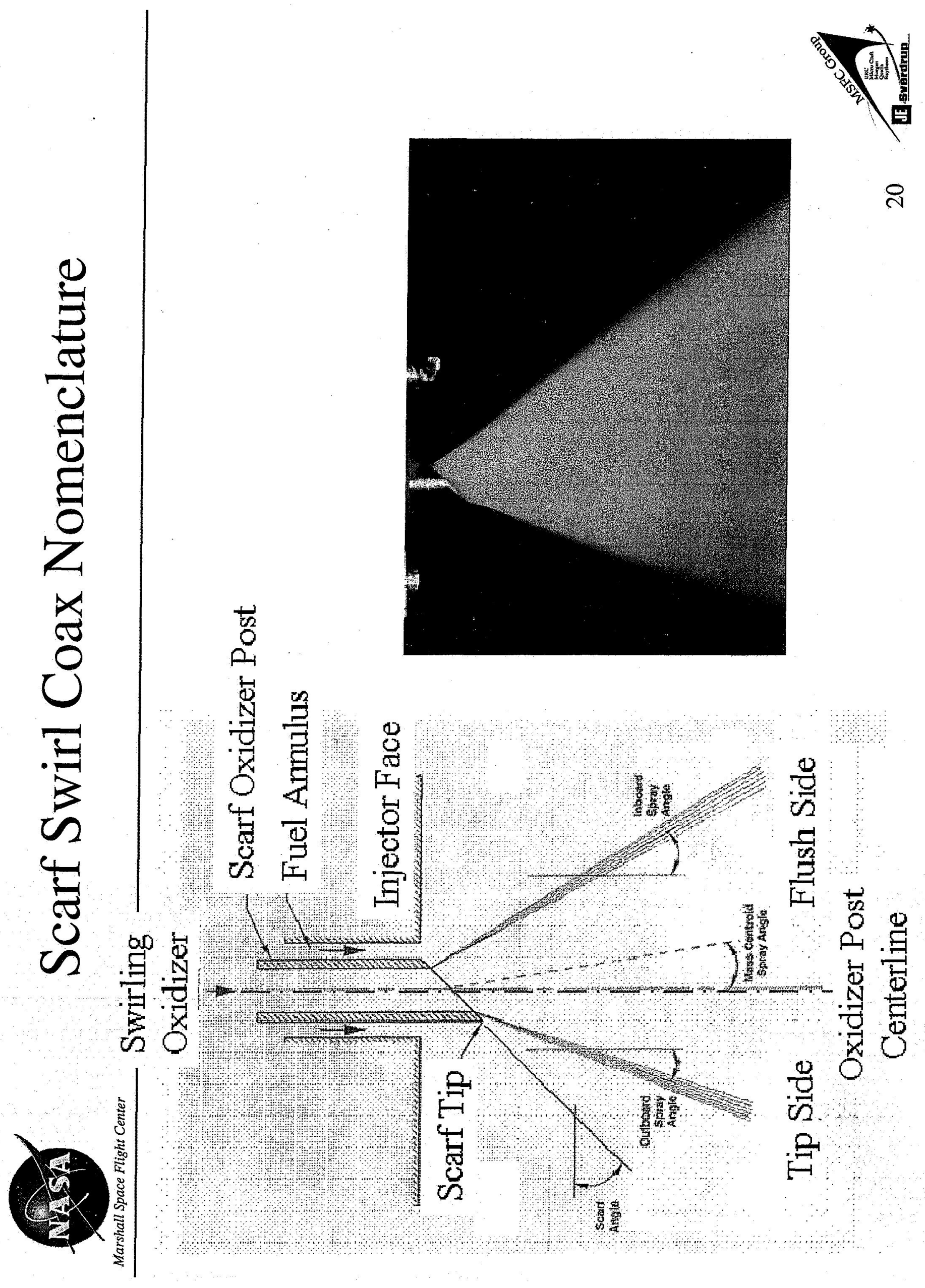




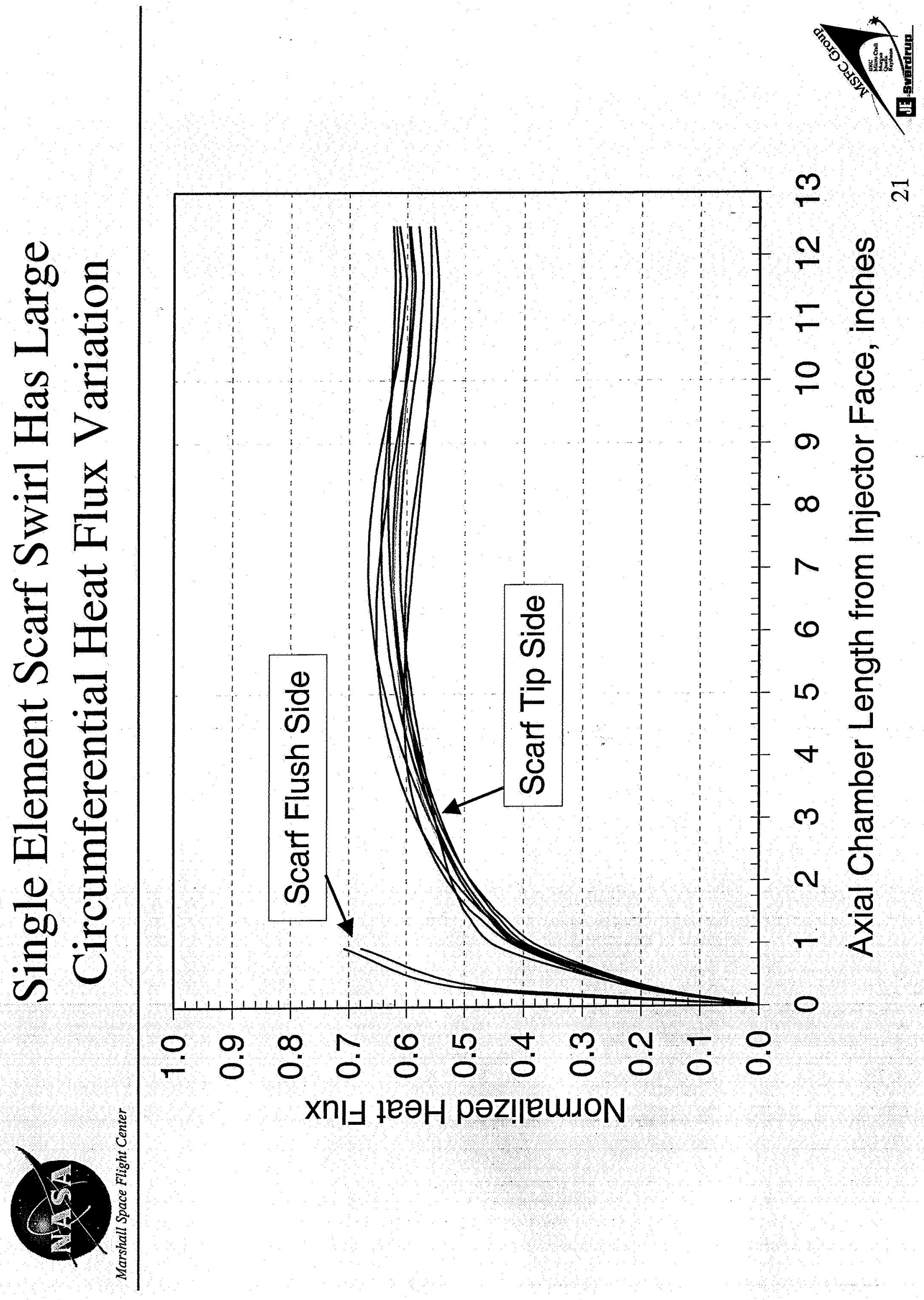




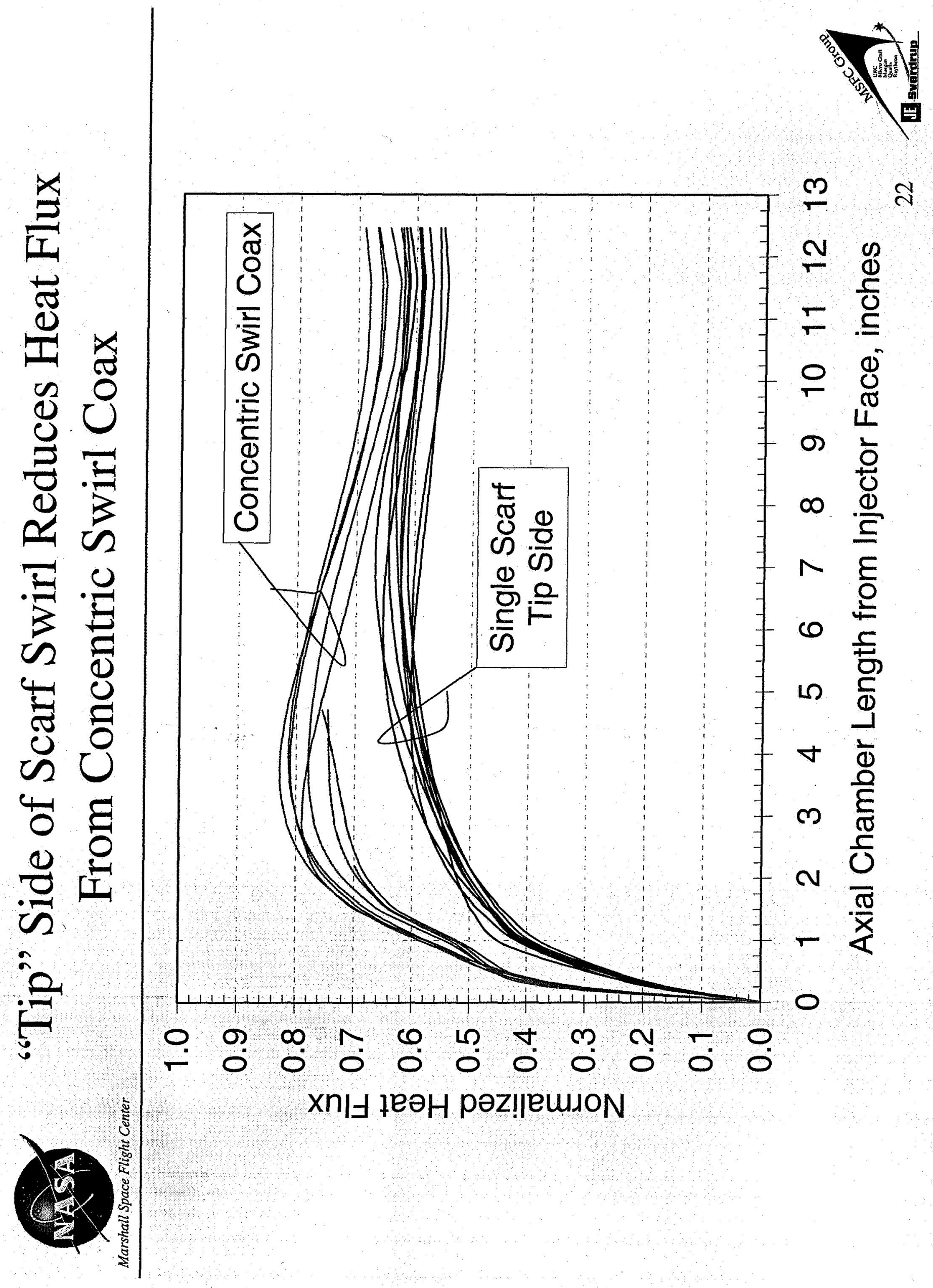




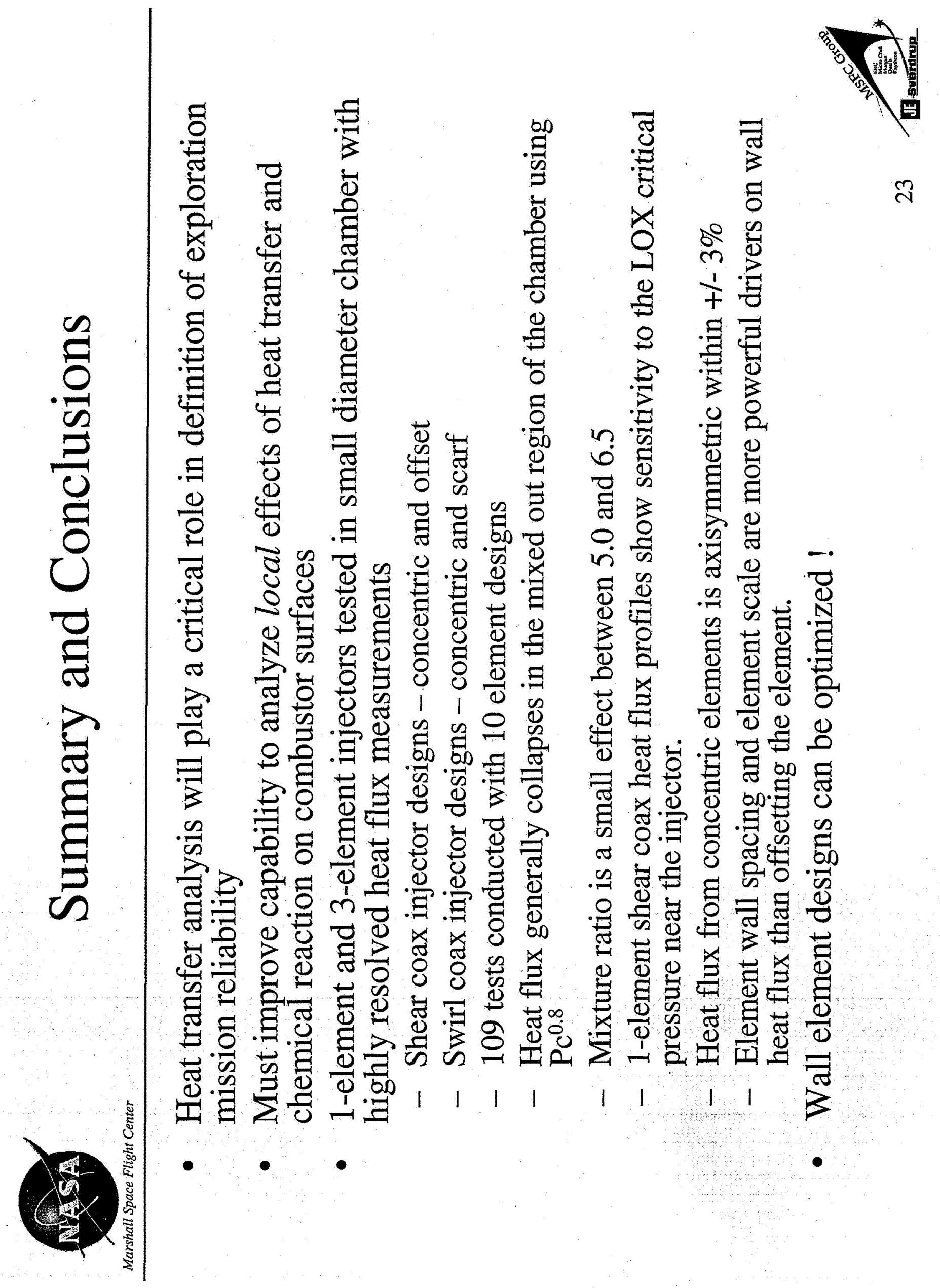




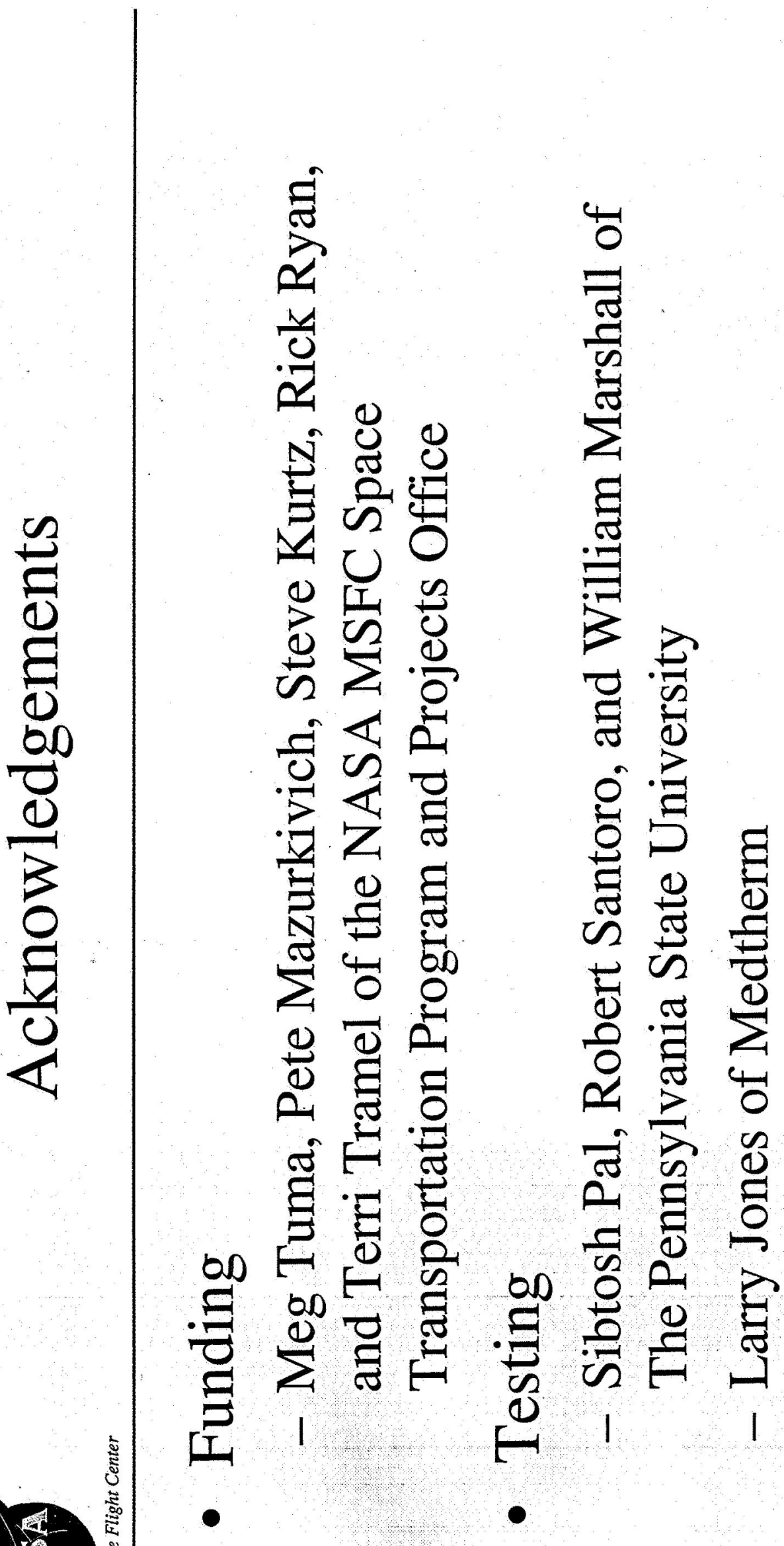

ป 

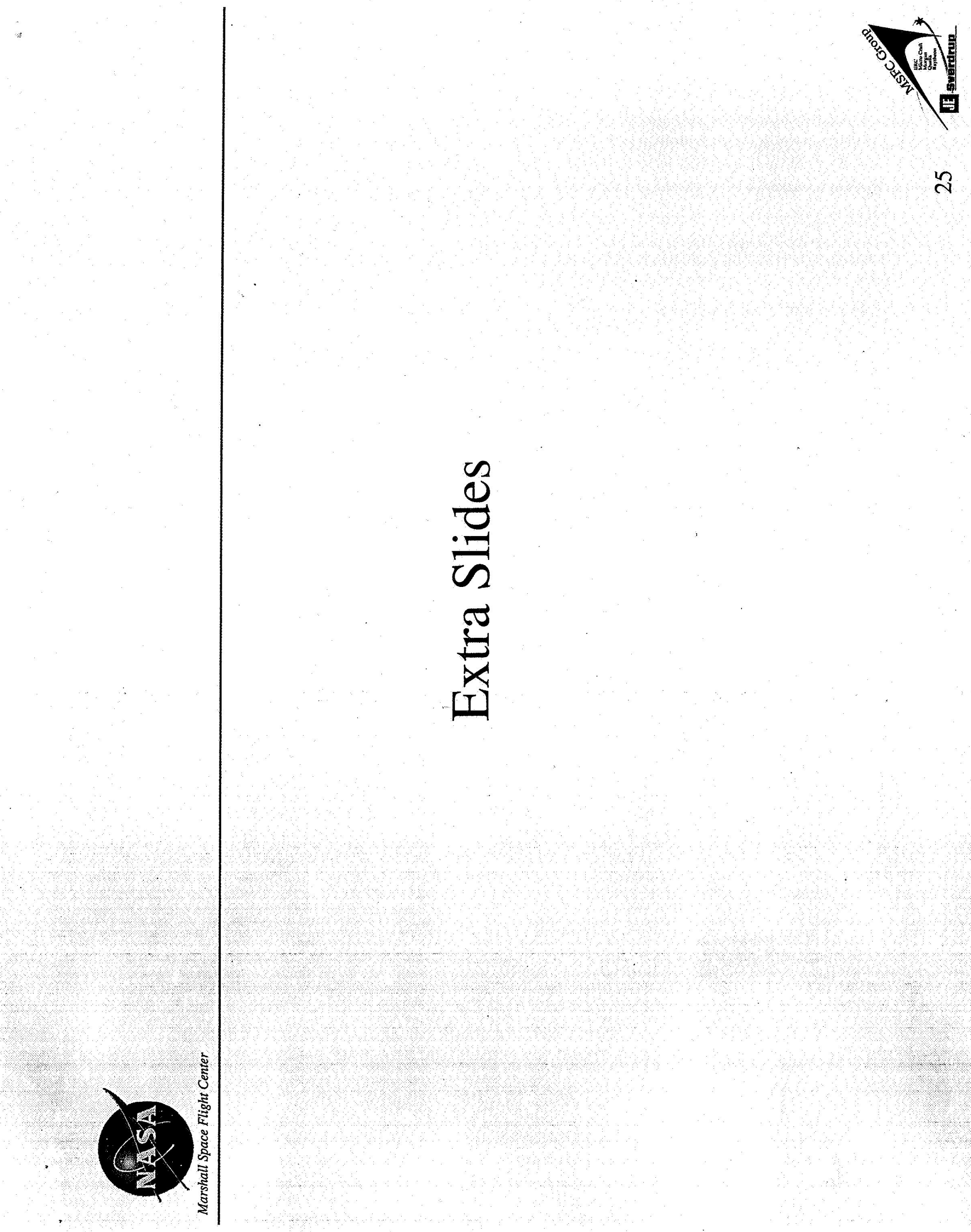

ก

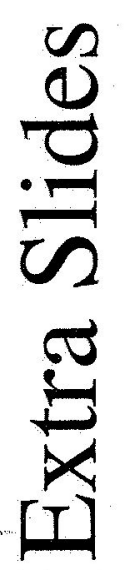




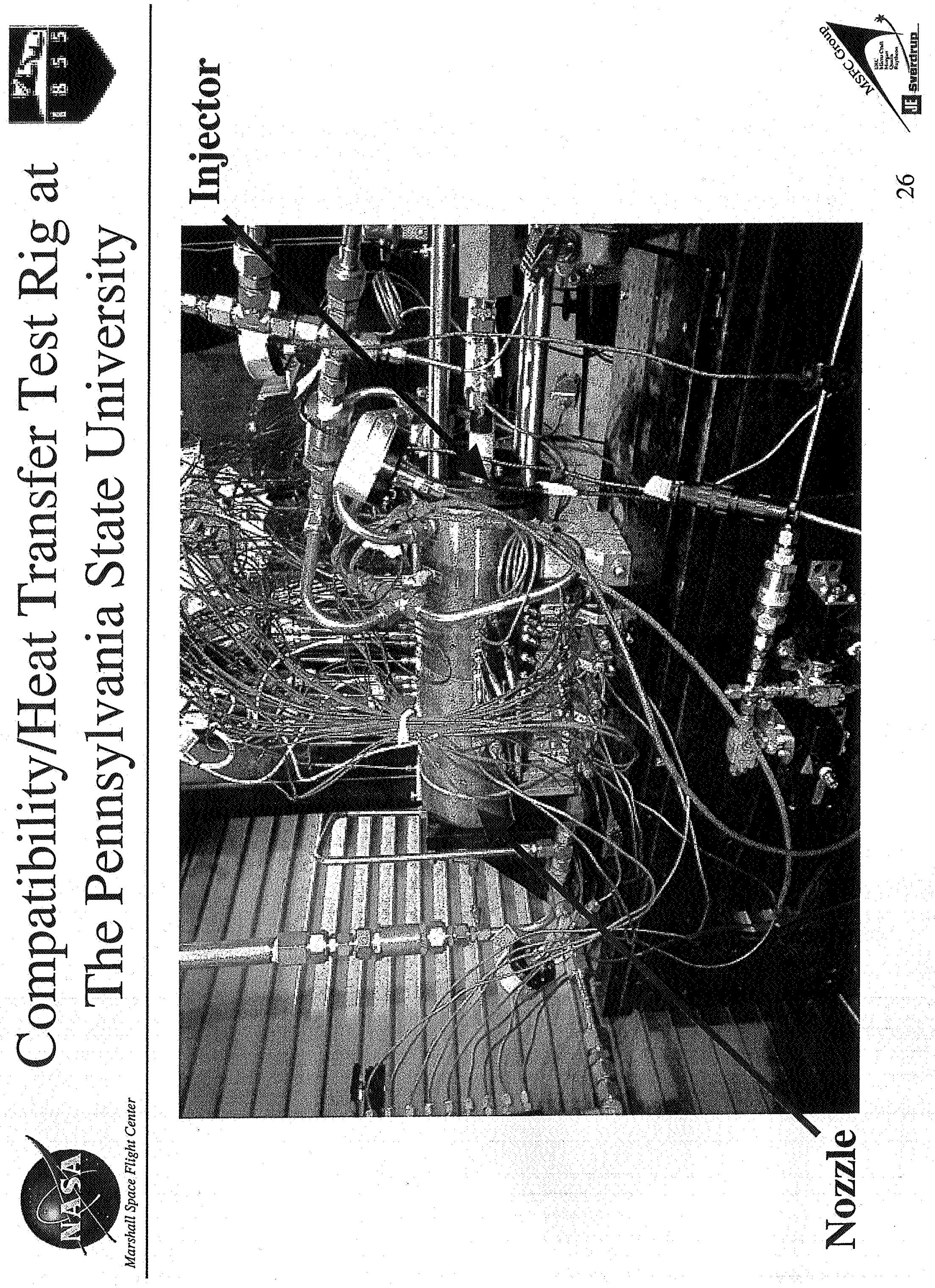




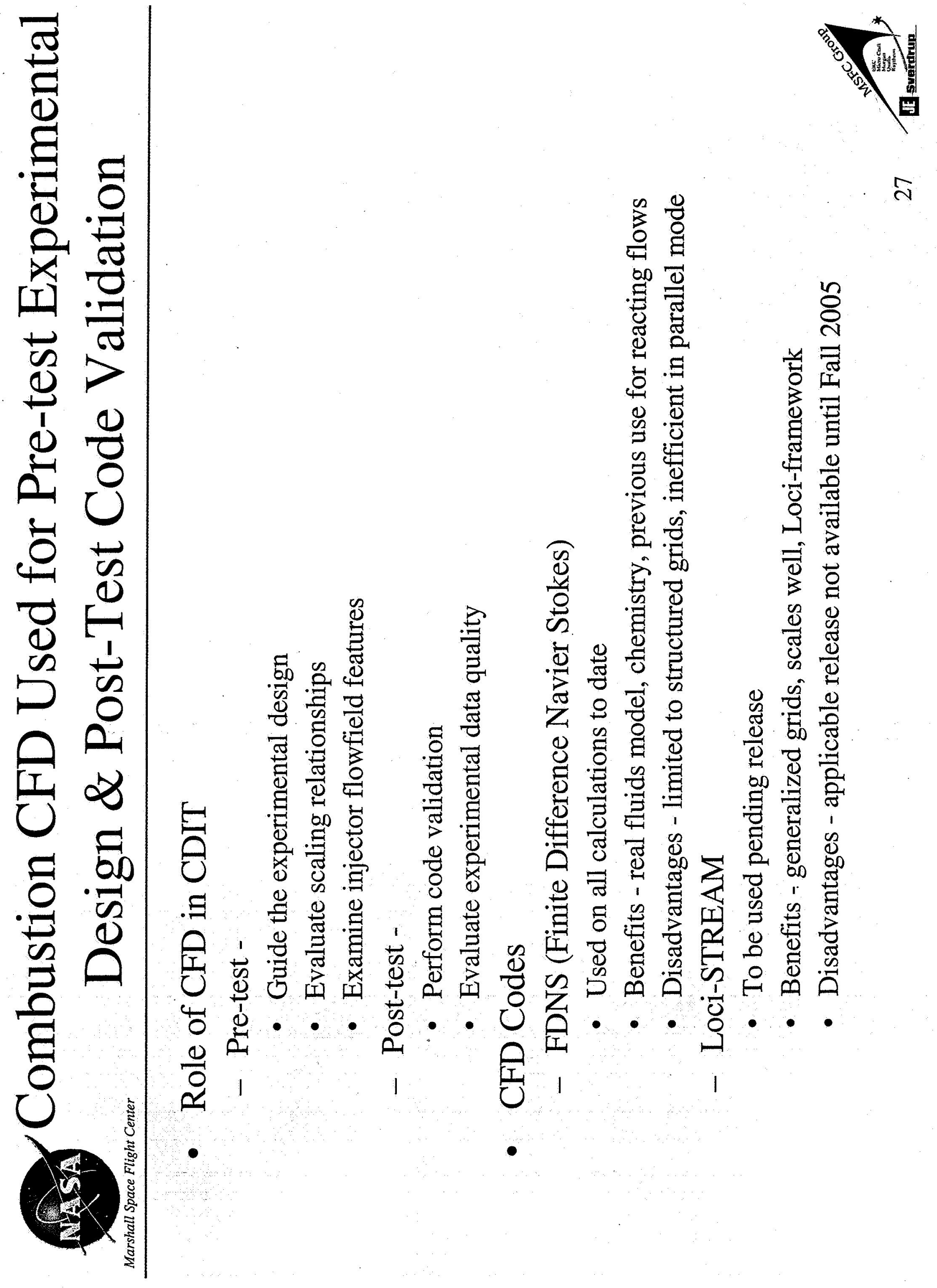




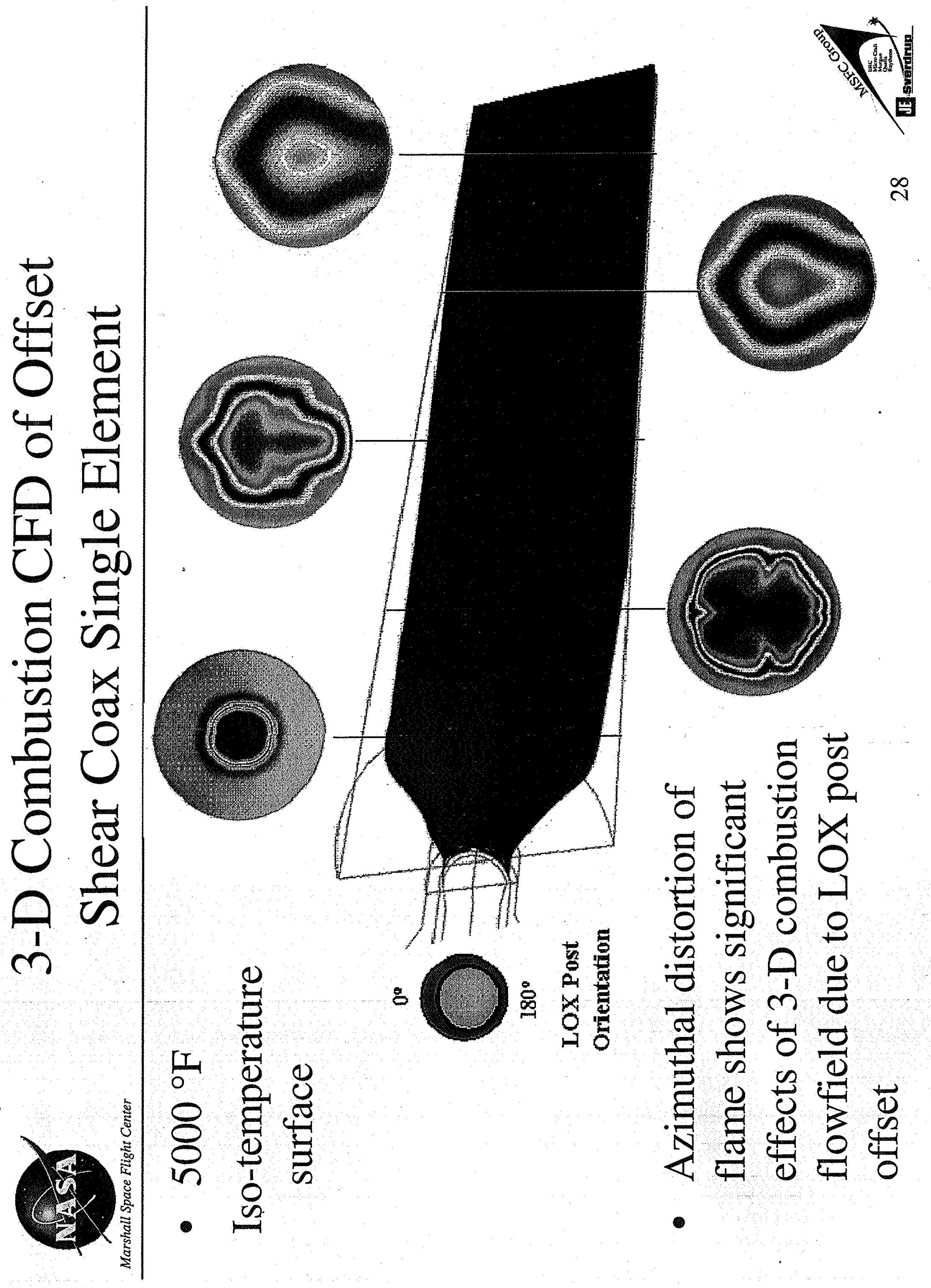




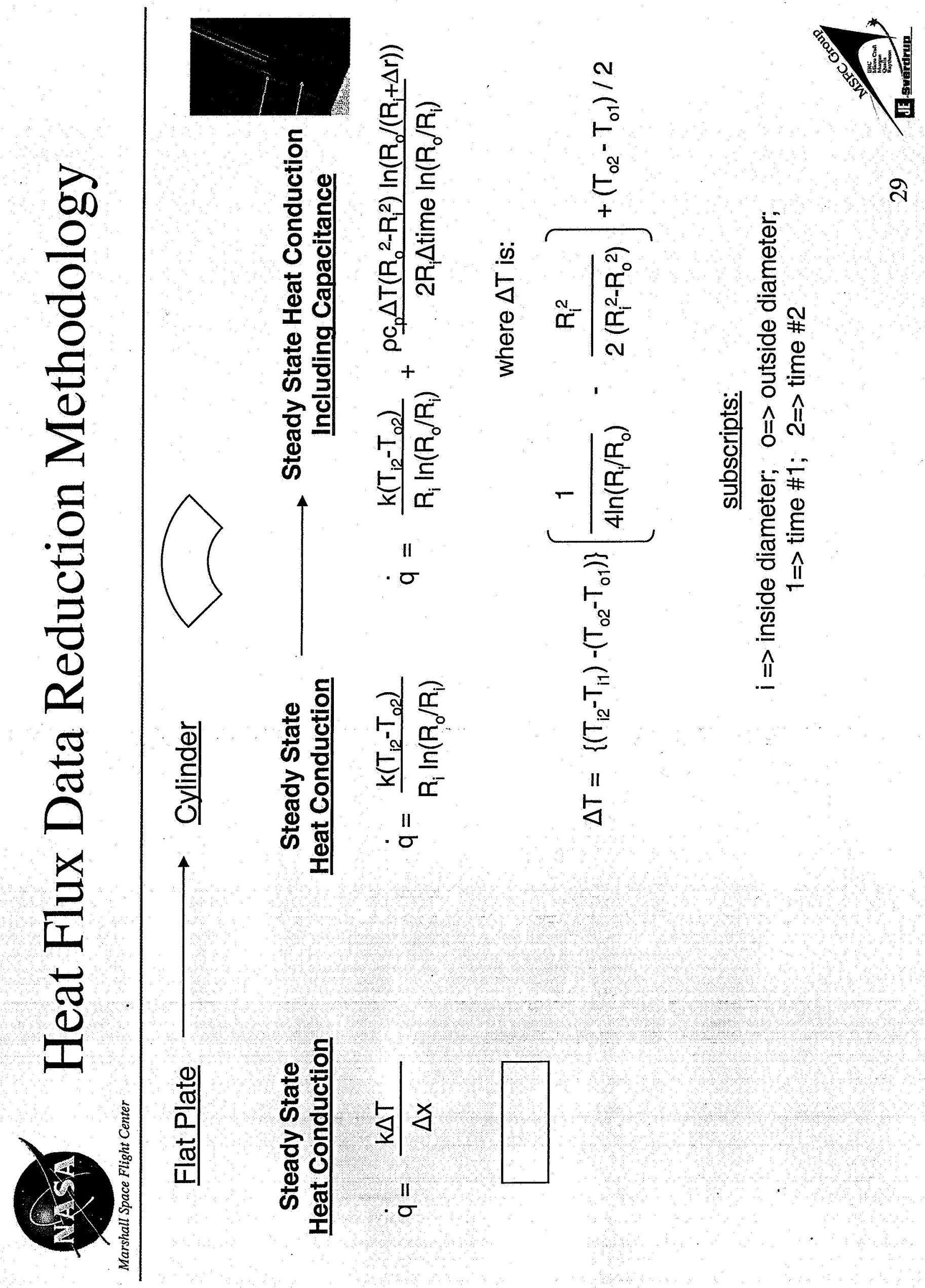




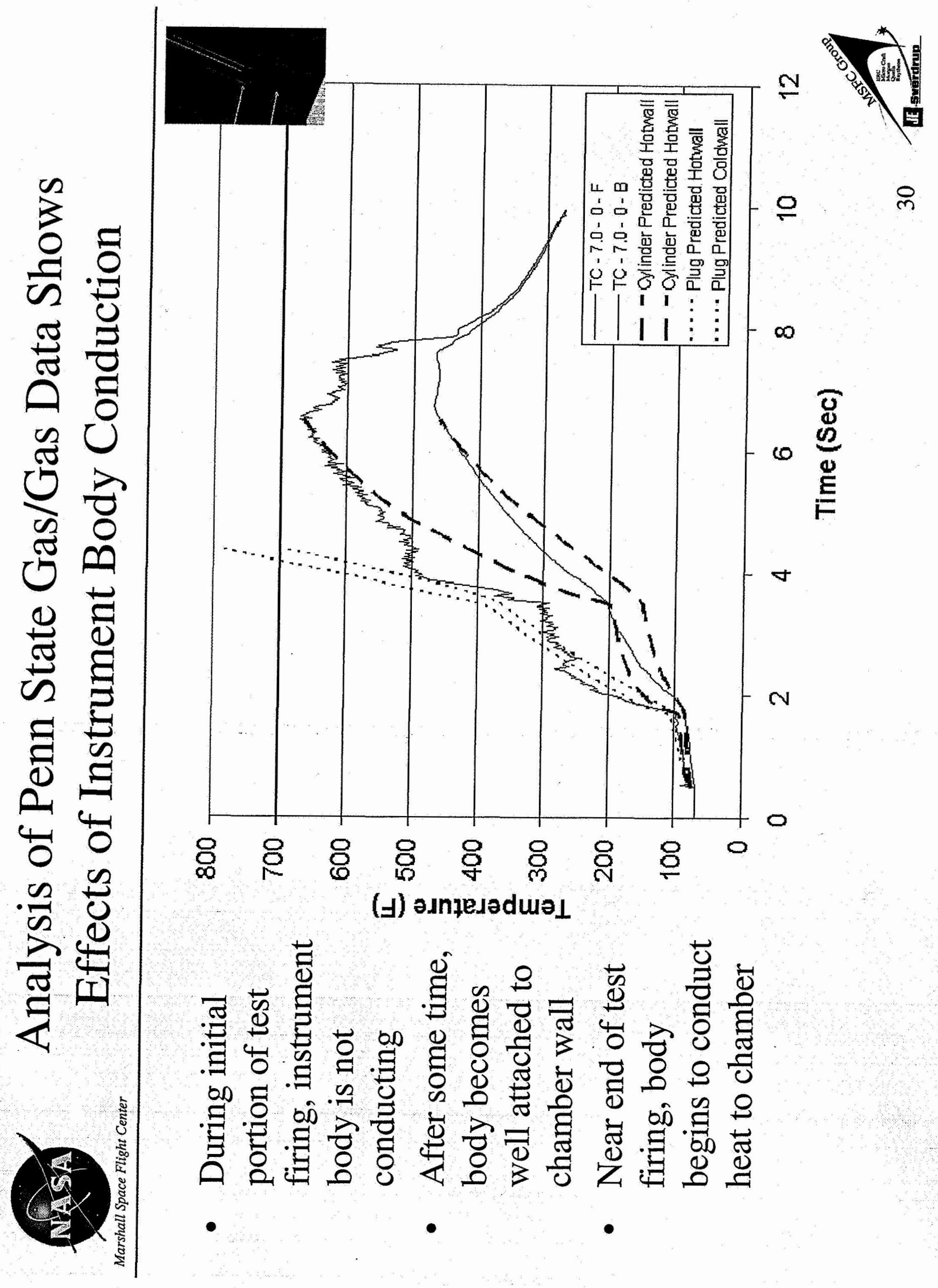

